\title{
Lactobacillus johnsonii BS15 improves intestinal environment against fluoride-induced memory impairment in mice-A study based on the gut-brain axis hypothesis
}

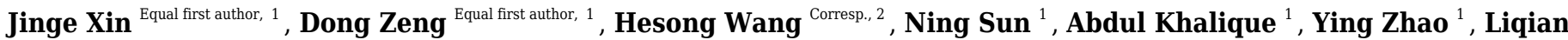 \\ Wu $^{1}$, Kangcheng Pan ${ }^{1}$, Bo Jing ${ }^{1}$, Xueqin Ni ${ }^{\text {Corresp. } 1}$ \\ ${ }^{1}$ Animal Microecology Institute, College of Veterinary Medicine, Sichuan Agricultural University, Chengdu, Sichuan, China \\ 2 Department of Gastroenterology, Guangdong Provincial Key Laboratory of Gastroenterology, Institute of Gastroenterology of Guangdong Province, \\ Nanfang Hospital, Southern Medical University, Guangzhou, China \\ Corresponding Authors: Hesong Wang, Xueqin $\mathrm{Ni}$ \\ Email address: sunasa1030@foxmail.com, xueqinni@foxmail.com
}

Background. Excessive fluoride can lead to chronic neurodegeneration characterized by neuron and myelin loss and memory dysfunction. The gut-brain axis hypothesis suggests that gut microbiota plays a crucial role in regulating brain function. Thus, using probiotics to adjust the gut microenvironment may be a potential therapy for mental diseases.

Methods. Mice in the prob group were administrated with Lactobacillus johnsonii BS15 for 28 days prior to and throughout a 70-day exposure to sodium fluoride. The drinking water of all groups ( $\mathrm{F}$ and prob groups) except the control group were replaced by high-fluoride water (100 mg NaF/L) on day 28. Animals in each group were divided into two subsets: one underwent behavioral test, and the other was sacrificed for sampling. The mRNA expression level and protein content related to inflammatory reaction in the ileum and hippocampus were respectively detected by reverse transcription quantitative polymerase chain reaction (RT-qPCR) and enzyme-linked immunosorbent assay (ELISA). The mRNA expression levels of proteins related to myelin structure, apoptosis, and memory in the hippocampus and tight junction proteins in the ileum were determined by RT-qPCR and/or immunohistochemistry. Gut permeability markers (D-lactate and diamine oxidase [DAO]) in the serum were also examined by ELISA.

Results. The results showed that fluoride exposure induced a lower spontaneous exploration $(P<0.05)$ in T-maze test, which indicated an impairment of memory. Spontaneous exploration of BS15-treated mice was significantly higher $(P<0.05)$ than that in $\mathrm{F}$ group. Fluoride reduced $(P<0.05)$ levels of myelin structural protein (proteolipid protein) and neurogenesis-associated proteins (brain-derived neurotrophic factor and $\mathrm{CAMP} / \mathrm{Ca}^{2+}$ responsive element-binding protein), induced disordered inflammatory cytokines (TNF- $\alpha$, IFN- $\gamma$, and IL-6; $P<0.05$ ), increased pro-apoptotic genes (caspase-3; $P<0.05$ ), and decreased antiapoptotic genes $(B C l-2 ; P<0.05)$ in the hippocampus, of which the influences were reversed by BS15. BS15 treatment exerted significant preventive effects on reversing the gut inflammation induced by excessive fluoride intake by reducing $(P<0.05)$ the levels of pro-inflammatory cytokines (tumor necrosis factor-alpha $[T N F-\alpha]$ and interferon-gamma $[I F N-\gamma])$ and remarkably increasing $(P<0.05)$ the level of antiinflammatory cytokines (IL-10). Moreover, the serum DAO activity and D-lactate concentration significantly increased by fluoride were also reduced $(P<0.05)$ by BS15. This result indicated the profitable effect of BS15 on gut permeability.

Conclusion: L. johnsonii BS15 intake could benefit the neuroinflammation and demyelination in the hippocampus by improving the gut environment and ameliorating fluorine-induced memory dysfunction.

Peer] reviewing PDF | (2020:02:46283:3:0:CHECK 4 Sep 2020) 


\section{Lactobacillus johnsonii BS15 improves intestinal}

\section{2 environment against fluoride-induced memory impairment}

\section{3 in mice-A study based on the gut-brain axis hypothesis}

4 Jinge $\mathrm{Xin}^{1 \dagger}$, Dong Zeng ${ }^{1 \dagger}$, Hesong Wang ${ }^{2 *}$, Ning Sun ${ }^{1}$, Abdul Khalique ${ }^{1}$, Ying Zhao ${ }^{1}$, Liqian

$5 \mathrm{Wu}^{1}$, Kangcheng $\mathrm{Pan}^{1}$, Bo Jing ${ }^{1}$, Xueqin $\mathrm{Ni}^{1 *}$

71 Animal Microecology Institute, College of Veterinary Medicine, Sichuan Agricultural

8 University, Chengdu, Sichuan, China.

92 Guangdong Provincial Key Laboratory of Gastroenterology, Department of Gastroenterology,

10 Institute of Gastroenterology of Guangdong Province, Nanfang Hospital, Southern Medical

11 University, Guangzhou, China.

12

13

14

15

16

17

18

19

${ }^{\dagger}$ Jinge $\mathrm{Xin}^{1}$ and Dong Zeng ${ }^{1}$ are equal contributors.

*Corresponding author:

Xueqin $\mathrm{Ni}^{1}$

211 Huimin Road, Chengdu 610400, Sichuan, China

E-mail: xueqinni@foxmail.com

Hesong Wang ${ }^{2}$

1838 Guangzhou Avenue, Guangzhou 510000, Guangdong, China

E-mail: sunasa1030@foxmail.com

\section{Abstract}

Background. Excessive fluoride can lead to chronic neurodegeneration characterized by neuron and myelin loss and memory dysfunction. The gut-brain axis hypothesis suggests that gut microbiota plays a crucial role in regulating brain function. Thus, using probiotics to adjust the gut microenvironment may be a potential therapy for mental diseases.

Methods. Mice in the prob group were administrated with Lactobacillus johnsonii BS15 for 28 days prior to and throughout a 70-day exposure to sodium fluoride. The drinking water of all groups ( $\mathrm{F}$ and prob groups) except the control group were replaced by high-fluoride water (100 $\mathrm{mg} \mathrm{NaF/L}$ ) on day 28. Animals in each group were divided into two subsets: one underwent behavioral test, and the other was sacrificed for sampling. The mRNA expression level and 
32 protein content related to inflammatory reaction in the ileum and hippocampus were respectively detected by reverse transcription quantitative polymerase chain reaction (RT-qPCR) and enzyme-linked immunosorbent assay (ELISA). The mRNA expression levels of proteins related to myelin structure, apoptosis, and memory in the hippocampus and tight junction proteins in the ileum were determined by RT-qPCR and/or immunohistochemistry. Gut permeability markers (D-lactate and diamine oxidase [DAO]) in the serum were also examined by ELISA.

Results. The results showed that fluoride exposure induced a lower spontaneous exploration $(P<0.05)$ in T-maze test, which indicated an imparement of memory. Spontaneous exploration of BS15-treated mice was significantly higher $(P<0.05)$ than that in $\mathrm{F}$ group. Fluoride reduced $(P<0.05)$ levels of myelin structural protein (proteolipid protein) and neurogenesis-associated proteins (brain-derived neurotrophic factor and $\mathrm{cAMP} / \mathrm{Ca}^{2+}$ responsive element-binding protein), induced disordered inflammatory cytokines $(T N F-\alpha, I F N-\gamma$, and $I L-6 ; P<0.05)$, increased proapoptotic genes (caspase-3; $P<0.05)$, and decreased anti-apoptotic genes $(B c l-2 ; P<0.05)$ in the hippocampus, of which the influences were reversed by BS15. BS15 treatment exerted significant preventive effects on reversing the gut inflammation induced by excessive fluoride intake by reducing $(P<0.05)$ the levels of pro-inflammatory cytokines (tumor necrosis factoralpha $[T N F-\alpha]$ and interferon-gamma $[I F N-\gamma])$ and remarkably increasing $(P<0.05)$ the level of anti-inflammatory cytokines $(I L-10)$. Moreover, the serum DAO activity and D-lactate concentration significantly increased by fluoride were also reduced $(P<0.05)$ by BS15. This result indicated the profitable effect of BS15 on gut permeability.

Conclusion: L. johnsonii BS15 intake could benefit the neuroinflammation and demyelination in the hippocampus by improving the gut environment and ameliorating fluorine-induced memory dysfunction.

\section{Introduction}

Excessive fluoride intake has attracted increasing attention because of its widely introduced sources and adverse effects on human health. Fluoride concentration in the groundwater could range from under $1 \mathrm{mg} / \mathrm{L}$ to more than $35 \mathrm{mg} / \mathrm{L}$ (Petrone et al., 2013). In addition, fluoride concentration in drinking tea (especially Chinese brick tea) ranges from 600-2800 mg/kg (Fung et al.,1999). The risk of high fluoride intake from food is also increasing because of the increased fluorine-containing crop protection compounds (Maienfisch \& Hall, 2004). The most well-known fluoride-induced negative influences are on teeth (dental fluorosis) (Sabokseir , Golkari \& Sheiham, 2016) and skeleton (skeletal fluorosis) (Littleton et al., 1999; Wang et al., 2019). Workers exposed to high fluoride suffer from drowsiness and impaired learning and 
65 memory (Czerwiński \& Lankosz, 1978). Furthermore, epidemiological investigation from China 66 (Wang et al., 2007), India (Sebastian \& Sunitha, 2015), Mexico (Bashash et al., 2017), and Iran 67 (Razdan et al., 2017) reported that children residing in endemic areas show deficits in learning and memory abilities. Rodents exposed to excessive fluoride also showed poor performances in memory-related behavioral tests in animal experiments (Chen et al., 2018; Liu et al., 2010). Animal experiments concerning fluoride neurotoxicity demonstrated that high fluoride exposure causes the pathological alteration of the synaptic ultrastructure of the hippocampus (Qian et al., 2013). Niu et al. (2018) suggested that fluoride could reduce neurotrophy and neuron adhesion and consequently damage the myelin in the hippocampus of mice.

Few safe and effective methods can protect the brain from fluoride neurotoxicity. The gut-brain axis, a bi-directional communication system linking the gut and brain, has provided a new insight into the treatment of brain-derived diseases (Forsythe \&Kunze, 2013). Recent advances in metagenomics confirmed that the relationship between diet and gut microbiota is a critical modulator underlying neurodevelopmental and psychiatric disorders in adults (Mayer, 2011). Germ-free mice and antibiotic-treated mice have exhibited lower performance in a series of memory behavioral test than normal animals. This finding suggested that a disturbed gut microbiota is associated with memory dysfunction and brain-derived neurotrophic factor $(B D N F)$ reduction (Arentsen et al, 2015; Bercik et al, 2011; Desbonnet et al, 2014). Similarly, exposure to fluoride can induce the imbalance of microbiological composition. Yasuda et al. (2017) found that fluoride exposure causes a depletion of acidogenic bacterial genera in oral community. Luo et al. (2016) reported that excessive fluoride intake induces a reduction of Lactobacillus spp. in the gut of broiler chickens. Moreover, previous studies demonstrated that mental diseases and cognitive functions can be effectively modulated by supplying probiotics or prebiotics to enhance the intestinal environment (Sgritta et al, 2019; Gareau et al, 2011). Therefore, we speculated that a potential link between disordered gut physiology and fluoride neurotoxicity could be utilized in preventing fluoride-induced memory dysfunction. However, little evidence has clearly demonstrated this relationship, and no probiotic has been proven effective on preventing fluoride-induced dysfunctions in the brain.

Therefore, the present study aimed to assess whether fluoride could alter gut physiology. Lactobacillus johnsonii BS15 was used to revert the altered intestinal physiology to further reveal whether fluoride neurotoxicity is associated with intestinal physiology and assess whether BS15 could be an effective strategy to control fluoride-induced memory dysfunction and hippocampal injury. The hippocampus is critical for bacteria-cognition link, as well as learning and memory (Stachenfeld, Botvinick \& Gershman, 2017), because of its lifetime synaptic plasticity and neurogenesis (Greenberg, Ziff \& Greene, 1986; Deisseroth \& Tsien 2002; Hong et 
100

101

102

103

104

105

106

107

108

109

110

111

112

113

114

115

116

117

118

119

120

121

122

123

124

125

126

127

128

129

130

al., 2008), thus, changes in hippocampal chemistry were given more attention in this study. The expression of neuronal activity-regulated genes, such as the immediate-early gene $c$-fos, $B D N F$, and neuronal cell adhesion molecule $(N C A M)$, play a critical role in synaptic plasticity (Hong et al., 2008; Simpson \& Morris 2000). Neurotrophin- and activity-dependent gene expression is mediated by cAMP/Ca ${ }^{2+}$ responsive element-binding protein (CREB) (Mantamadiotis et al., 2002). Moreover, BDNF, CREB, NCAM, and stem cell factor (SCF) are essential for neurogenesis.

\section{Materials \& Methods}

\section{Materials and methods}

\section{Culture and treatment with BS15}

L. johnsonii BS15 (CCTTCC M2013663) was isolated from homemade yogurt collected from Hongyuan Prairie, Aba Autonomous Prefecture, China. Our previous study demonstrated that BS15 can effectively prevent non-alcoholic fatty liver disease by attenuating mitochondrial lesion and inflammation in the liver, lowering intestinal permeability, and adjusting gut microbiota (Xin et al., 2014). Thus, BS15 was selected as the potential treatment strategy to improve gut flora in the present study. L. johnsonii BS15 was cultured anaerobically in de ManRogosa-Sharpe broth (Qingdao Rishui Bio-technologies Co., Ltd., Qingdao, China) at $37^{\circ} \mathrm{C}$. The amounts of bacterial cells were evaluated by heterotrophic plate count. Briefly, the cultures were centrifuged, washed, and resuspended in phosphate buffered saline (PBS; pH 7.0) for experimental use. The concentration of BS15 suspension was $1 \times 10^{9} \mathrm{cfu} / \mathrm{mL}$ (daily consumption dose: $0.2 \mathrm{~mL} / \mathrm{mice}$ ).

\section{Behavioral tests}

\section{Novel object recognition (NOR) test}

The NOR test is a widely used method for the investigation of working memory alteration. The results of NOR test reflects the function of the hippocampus based on the nature propensity of mice to a novel object rather than a familiar one. The task procedure consists three phases (Antunes \& Biala, 2012): habituation, familiarization, and test phase. Briefly, in the habituation phase, each mouse was allowed to freely explore the open-field arena $(40 \times 40 \times 45 \mathrm{~cm}, 1 \times b \times \mathrm{h})$ for $1 \mathrm{~h}$ in the absence of objects. The mouse was then removed from the arena and placed in its home cage. During the familiarization phase, each mouse was placed in the arena to freely explore two different objects (\#A+\#B) for $5 \mathrm{~min}$. The two objects were placed in the opposite 
131

132

133

134

135

136

137

138

139

140

141

142

143

corners of the cage. The mouse was given an intermediate retention interval of $20 \mathrm{~min}$ and then returned to the arena and re-exposed to object $\mathrm{B}$ along with a completely new object (object $\# \mathrm{C}$, distinguishable from object $\# \mathrm{~A})$. Exploration ratio $(\mathrm{F} \# \mathrm{C} /(\mathrm{F} \# \mathrm{C}+\mathrm{F} \# \mathrm{~B}) \times 100$, where $\mathrm{F} \# \mathrm{C}=$ frequency of exploring object $\# \mathrm{C}$, and $\mathrm{F} \# \mathrm{~B}$ = frequency of exploring object $\# \mathrm{~B}$ ) was calculated to assess memory. The objects used included a green bottle cap (\#A), an orange bottle cap (\#B), and a small smooth stone ( $\# \mathrm{C})$.

\section{T-maze test}

An enclosed T-maze, which is an equipment with $10 \mathrm{~cm}$-wide floor and $20 \mathrm{~cm}$-high walls in the form of a "T", was placed horizontally. The stems of two goal arms and a start arm were $30 \mathrm{~cm}$ long. A central partition in the middle of the two goal arms extended into the start $\operatorname{arm}(7 \mathrm{~cm})$. Every arm had a guillotine door. The equipment and the operating steps were consistent with those of Deacon and Rawlins (2006). First, the central partition was put in the T-maze with all doors open. Then, each mouse was placed in the start area directly from its home cage and allowed to choose the left or right arm. The mouse was kept in the chosen arm by quietly sliding the door down. After $30 \mathrm{~s}$, the mouse and central partition were removed, and the mouse was placed back into its holding cage. After a retention interval of $1 \mathrm{~min}$, the mouse was placed back into the start area for a second trial with all doors open. Each mouse was given ten trials over five days and allowed to explore the maze before sated. The trial was marked as "correct" if the mouse chooses the other goal arm in consecutive trials. Each exploration should take no more than $2 \mathrm{~min}$.

\section{Establishment of animal model and study design}

Forty-eight male ICR mice (3 week-old, Dashuo Biological Institute, Chengdu, Sichuan, China) were fed with normal chow diet (Dashuo Biological Institute, Chengdu, Sichuan, China) for 1 week to acclimatize to the new environment. After the adaptation period, the mice were equally and randomly divided into three groups and administered with either $0.2 \mathrm{~mL}$ of PBS (control group, F group) or BS15 (prob group) every day by gavage throughout a 98-day experimental period. Animals in the $\mathrm{F}$ and prob groups were exposed to $100 \mathrm{mg} / \mathrm{L}$ fluoride in drinking water from the 28th day to the 98th day. The mice were housed in an animal facility with a humidity of $40 \%-60 \%$, a temperature of $20-22{ }^{\circ} \mathrm{C}$ and a $12-\mathrm{h}$ light/dark cycle (lights off at 6:00 a.m. and on at 6:00 p.m.). We housed five or six mice per cage bedded by wood shavings and with food and water available ad libitum. The wood shavings were replaced every 2 days. Drinking water was replaced and water bottles were washed every 5 days. All animal experiments were performed according to the guidelines for the care and use of laboratory animals approved by the Institutional Animal Care and Use Committee of Sichuan Agricultural University (Approval 
165

166

167

168

169

170

171

172

173

174

175

176

177

178

179

180

181

182

183

184

185

186

187

188

189

190

191

192

193

194

195

196

197

number: SYXKchuan2019-187). Ten mice from each group were selected for behavioral test on the 98th day of the experiment. The other six mice of each group were sacrificed by cervical dislocation to collect tissues. The behavior test and sampling were carried out from 7:00 a.m. to $11: 30$ a.m.

Blood was sampled from the mice orbit, and the serum was separated by incubation at $4{ }^{\circ} \mathrm{C}$ for $30 \mathrm{~min}$ followed by centrifugation at $2,000 \times \mathrm{g}$ for $20 \mathrm{~min}$ and stored at $-30{ }^{\circ} \mathrm{C}$. Tissues from the left hippocampus and partial ileum were removed and washed with ice-cold sterilized saline and then immediately frozen in liquid nitrogen for gene expression analysis. Tissues from the right hippocampus and partial ileum were ground $(\mathrm{pH} 7.4)$ into $5 \%$ and $10 \%$ homogenates, respectively, with PBS and then centrifuged at $12,000 \times \mathrm{g}$ for $5 \mathrm{~min}$ at $4{ }^{\circ} \mathrm{C}$. The obtained supernatant was stored at $-80^{\circ} \mathrm{C}$ for further detection.

\section{Biochemical evaluation}

The contents of corticosterone, D-lactate, and diamine oxidase (DAO) in the serum; inflammatory cytokines in the supernatant of hippocampal and ileal homogenates; and the apoptosis-regulated proteins in the supernatant of the hippocampal homogenate were measured by commercial enzyme-linked immunosorbent assay (ELISA) kit (Enzyme-linked Biotechnology Co., Ltd., Shanghai, China) specific for mice. The inflammatory cytokines included tumor necrosis factor-alpha (TNF- $\alpha)$, interferon-gamma (IFN- $\gamma)$, interleukin-1 $\beta(I L-1 \beta), I L-6$, and $I L-10$ (only detected in ileum tissue). The operation was performed strictly according to the manufacturer's instructions.

\section{Real-time quantitative polymerase chain reaction (RT-qPCR) analysis of gene expression}

Total hippocampal RNA and ileal RNA were isolated using E.Z.N.A.® Total RNA Kit (OMEGA Bio-Tek, Doraville, GA, USA) according to the manufacturer's instructions. The isolated RNA was assessed for the ratio of absorbances at 260 and $280 \mathrm{~nm}$ and by agarose gel electrophoresis for quantitative and qualitative analyses. The isolated RNA was transcribed into first-strand complementary DNA (cDNA) with PrimeScript RT reagent kit with gDNA Eraser (Thermo Scientific, Waltham, Massachusetts, USA) according to the manufacturer's instructions. The cDNA products were stored in $-80{ }^{\circ} \mathrm{C}$ for further use. qPCR was performed using CFX96 RT PCR Detection System (Bio-Rad, Hercules, CA, USA) and SYBR Premix Ex TaqTM PCR Kit (Bio-Rad, Hercules CA, USA) to quantify the relative expression levels of neuroplasticity-related factors ( $B D N F, C R E B, S C F$, and $N C A M)$, early gene ( $c$-fos), molecular proteins related to myelin structure (myelin oligodendrocyte glycoprotein $[M O G]$, proteolipid protein $[P L P]$, myelin basic protein $[M B P]$, and myelin-associated glycoprotein $[M A G])$, and 
198

199

200

201

202

203

204

205

206

207

208

209

210

211

212

213

214

215

216

217

218

219

220

221

222

223

224

225

226

227

228

229

apoptosis-related proteins (B-cell lymphoma-2 [Bcl-2], B-cell lymphoma-extra large [Bcl-xl], $B c l$-2-associated X protein [Bax], Bcl-xl/Bcl-2-asociated death promoter [Bad], caspase-9, and caspase-3) and cytokines ( $I F N-\gamma, T N F-\alpha, I L-1 \beta, I L-6$, and $I L-10)$ in the hippocampus tissue and cytokines and tight junction (TJ) proteins (zonula occludens protein 1 [ZO-1], claudin-1, and occludin) in ileum tissue with $10 \mu \mathrm{L}$ total reaction volume. The thermocycle protocol was performed as follows: $5 \mathrm{~min}$ at $95{ }^{\circ} \mathrm{C}$, followed by 40 cycles of $10 \mathrm{~s}$ denaturation at $95^{\circ} \mathrm{C}$, and $30 \mathrm{~s}$ annealing/extension at optimum temperature (Table 1). A final melting curve analysis was performed to monitor the purity of the PCR product. $\beta$-actin was used as reference gene to

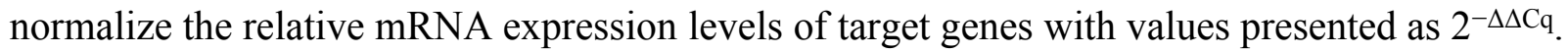
The primer sequences and optimum annealing temperatures are shown in Table 1.

\section{Immunohistochemistry}

A subset of mice in each group was sacrificed, and their brain was removed, fixed in $4 \%$ paraformaldehyde solution, and stored in $4{ }^{\circ} \mathrm{C}$ for immunohistochemical assay. The brain tissues were embedded by paraffin and cut by microtome. Slices were submerged in citrate antigen retrieval solution and heated on medium until boiling using a microwave (model: P70D20TL-P4; Galanz, Guangdong, China). The fire was ceased, and the tissues were kept warm for $8 \mathrm{~min}$. Then, the tissues were heated at medium-low heat for $7 \mathrm{~min}$. After free cooling, the slices were placed into PBS (pH 7.4) and shaken for 5 min for decoloration, which was repeated three times. Then, the sections were incubated in 3\% oxydol for $25 \mathrm{~min}$ at room temperature and away from light for blocking endogenous peroxidase. The slices were washed three times in PBS by shaking for $5 \mathrm{~min}$, then sealed for $30 \mathrm{~min}$ by $3 \%$ bull serum albumin, and incubated with monoclonal rabbit anti-BDNF (1:400) or polyclonal rabbit anti-CREB (1:500) at $4{ }^{\circ} \mathrm{C}$ overnight. Speciesspecific biotinylated anti-rabbit immunoglobulin (horseradish peroxidase-labeled) was used for immuno-detection. Following the second antibody incubation, 3,3'-diaminobenzidine staining kit was used to complete the reaction according to the manufacturer's instructions. Hematoxylin stain was performed to re-stain the nucleus. BDNF and CREB were quantified by calculating their integral optical density (IOD) in the object region (ImageJ, National Institutes of Health, USA). The average optical density (IOD/object region areas) was calculated, and the results were presented as levels of expression.

\section{Statistics}

Results were expressed as mean \pm standard deviation. One-way ANOVA was performed between different groups with IBM SPSS Statistics 25 (IBM Corporation). Differences of 
230

231

232

233

234

235

236

237

238

239

240

241

242

243

244

245

246

247

248

249

250

251

252

253

254

255

256

257

258

259

$P<0.05$ were considered statistically significant. The figures were plotted using GraphPad Prism version 7.04 (San Diego, CA, USA).

\section{Results}

\section{Behavioral results}

Figure 1A shows that the $\mathrm{F}$ group showed a lower spontaneous exploration (control vs. F, $P<0.01$; F vs. prob, $P=0.019)$ than the other two groups, but no difference $(P>0.05)$ was found between the control and prob groups $(P=0.104)$. The exploration ratio of the three groups were not significantly different (control vs. F, $P=0.125$; control vs. prob, $P=0.285$; F vs. prob, $P=0.626$; Fig. 1B).

\section{mRNA and protein expressions of $B D N F$ in the hippocampus}

Figure 2A shows that the $\mathrm{F}$ group presented a significant decrease in $B D N F$ mRNA level than the other two groups (control vs. F, $P<0.01$; F vs. prob, $P=0.014$ ), whereas the control and prob groups had no difference $(P=0.414)$. As shown in Fig. $2 \mathrm{~B}-\mathrm{E}$, the $B D N F$ protein level was decreased in the $\mathrm{F}$ group compared with the control $(P<0.01)$ and prob groups $(P=0.018)$. No difference was observed between the control and prob groups $(P=0.513)$.

\section{mRNA and protein expressions of $C R E B$ in the hippocampus}

As shown in Fig. 3A, CREB mRNA level was slightly reduced in the F group $(P=0.484)$ and increased in the prob group $(P=0.065)$ compared with the control group. The $C R E B$ mRNA level in the prob group was significantly $(P=0.026)$ higher than that in the $\mathrm{F}$ group. Figure $3 \mathrm{~B}-\mathrm{E}$ shows that the $\mathrm{F}$ group presented a significant decrease in $C R E B$ protein level than the other two groups (control vs. F, $P=0.048$; F vs. prob, $P<0.01$ ). $C R E B$ protein level in the prob group was remarkably higher than that in the control group $(P=0.032)$.

\section{mRNA expressions of $N C A M, S C F$, and $c$-fos in the hippocampus}

As shown in Fig. 4A, the control group had a higher NCAM mRNA level than the other two groups (control vs. F, $P=0.001$; control vs. prob, $P=0.001$ ), but no difference was found between the $\mathrm{F}$ and prob groups $(P=0.783)$. Figure $4 \mathrm{~B}$ shows that the $S C F$ mRNA level of the three groups were not significantly different (control vs. F, $P=0.105$; control vs. prob, $P=0.842$; F vs. prob, $P=0.181$ ). As shown in Fig. $4 \mathrm{C}$, the control group presented a higher mRNA expression of $\mathrm{c}$-fos than the other two groups (control vs. F, $P<0.01$; control vs. prob, $P<0.01$ ), but the expression of c-fos between the other two groups were not significantly different (F vs. prob, $P=0.449$ ). 
260

261

262

263

264

265

266

267

268

269

270

271

272

273

274

275

276

277

278

279

280

281

282

283

284

285

286

287

288

289

290

291

292

\section{Hippocampal inflammation}

Figures 5A and 5D show that the $T N F-\alpha$ (mRNA level: control vs. F, $P=0.013$; F vs. prob, $P=0.252$; protein level: control vs. F, $P<0.001$; F vs. prob, $P=0.001)$ and $I F N-\gamma$ (mRNA level: control vs. F, $P=0.007$; F vs. prob, $P=0.037$; protein level: control vs. F, $P<0.001$; F vs. prob, $P<0.001)$ in the $\mathrm{F}$ group were significantly or slightly higher than those in the other two groups in mRNA and protein levels. The $T N F-\alpha$ of the prob group was significantly increased in the protein level $(P<0.001)$ but not in the mRNA level $(P=0.115)$ compared with the control group (Fig. 5A). No difference in $I F N-\gamma$ (Fig. 5D) was observed between the control and prob groups in the mRNA $(P=0.381)$ and protein levels $(P=0.931)$. Figure $5 \mathrm{C}$ reveals that the $\mathrm{F}$ group had a remarkably lesser $I L-6$ than the other two groups in mRNA (control vs. F, $P<0.001$; F vs. prob, $P=0.011$ ) and protein levels (control vs. F, $P<0.001$; F vs. prob, $P<0.001$ ). As shown in Fig. 5C, the prob group presented a significantly lesser $I L-6$ than the control group in mRNA $(P<0.001)$ and protein levels $(P<0.001)$. The three groups had no remarkable change in $I L-1 \beta$ in the mRNA and protein levels (mRNA level: control vs. F, $P=0.089$; control vs. prob, $P=0.097$; F vs. prob, $P=0.962$; protein level: control vs. F, $P=0.420$; control vs. prob, $P=0.733$; F vs. prob, $P=0.636$ ). $I L-10$ did not reach the detection threshold (Fig. 5B).

\section{Hippocampal myelin and apoptosis-related proteins}

Fig. 6A shows the clear decreasing trend in the mRNA level of $P L P$ in the F group compared with the other two groups (control vs. F, $P<0.013$; F vs. prob, $P=0.0039$ ). A difference (control vs.prob, $P=0.568$ ) in the mRNA level of $P L P$ between the control and prob groups was not detected. Figure 6B shows that the control group had a higher $M O G$ mRNA level than the $\mathrm{F}$ and prob group (control vs. F, $P=0.005$; control vs. prob, $P=0.002$ ), whereas the $M O G$ mRNA level of the F group was not different $(P=0.778)$ from that of the prob group. Differences in the mRNA levels of $M B P$ (control vs. F, $P=0.277$; control vs.prob, $P=0.706$; F vs. prob, $P=0.415$; Fig. 6C) and $M A G$ (control vs. F, $P=0.904$; control vs. prob, $P=0.919$; F vs. prob, $P=0.970$; Fig. $6 \mathrm{D})$ were not observed among the three groups. Figures 7A and 7E present a remarkable (control vs. F, $P<0.026$; F vs. prob, $P=0.038$ ) decrease in $B c l-2$ mRNA level and a significant (control vs. $\mathrm{F}, P<0.033$; F vs. prob, $P=0.001)$ increase in caspase $-3 \mathrm{mRNA}$ level in $\mathrm{F}$ group compared with the other two groups, and the $B c l-2(P=0.948)$ and caspase- 3 mRNA levels $(P=0.127)$ of the control and prob groups were not significantly different. Figures 7B, 7C, 7D, and 7F reveal no significant differences $(P>0.05)$ among the three group in the mRNA levels of $B c l-x l$ (control vs. F, $P=0.290$; control vs. prob, $P=0.463$; F vs. prob, $P=0.735$ ), $B a x$ (control vs. F, $P=0.784$; control vs. prob, $P=0.681$; F vs. prob, $P=0.891$ ), $B a d$ (control vs. F, $P=0.954$; control vs. prob, 
293

294

295

296

297

298

299

300

301

302

303

304

305

306

307

308

309

310

311

312

313

314

315

316

317

318

319

320

321

322

323

324

325

$P=0.137$; F vs. prob, $P=0.124$ ), and caspase 9 (control vs. F, $P=0.128$; control vs. prob, $P=0.684$; F vs. prob, $P=0.197)$.

\section{Inflammatory factors in the ileum}

As shown in Fig. 8A, the F group exhibited a slight increase in $T N F-\alpha$ mRNA level $(P=0.079)$ and a significantly enhanced $T N F-\alpha$ protein level $(P<0.001)$ compared with the control group. $T N F-\alpha$ in the mRNA $(P=0.008)$ and protein levels $(P<0.001)$ were significantly reduced in the prob group compared with the F group. Differences in the mRNA $(P=0.197)$ and protein levels ( $P=0.348$ ) of $T N F-\alpha$ were not observed between the control and prob groups. The mRNA $(P=0.888)$ and protein levels $(P=0.781)$ of $I L-1 \beta$ (Fig. $8 \mathrm{~B})$ between the $\mathrm{F}$ and prob groups were not significantly different. $I L-1 \beta$ (Fig. $8 \mathrm{~B}$ ) in the control group showed a slight decrease in mRNA level (control vs. F, $P=0.132$; control vs. prob, $P=0.103$ ) and a remarkable (control vs. F, $P=0.003$; control vs. prob, $P=0.002$ ) decline in protein level compared with those in the other two groups (Fig. 8B). No difference was observed in $I L-6$ (Fig. 8C) in mRNA (control vs. F, $P=0.635$; control vs. prob, $P=0.615$; F vs. prob, $P=0.975$ ) and protein levels (control vs. F, $P=0.407$; control vs. prob, $P=0.908$; F vs. prob, $P=0.347)$ among the three groups. The $\mathrm{F}$ group exhibited a significantly increased $I F N-\gamma$ (mRNA level: control vs. F, $P<0.001$; F vs. prob, $P<0.001$; protein level: control vs. F, $P<0.001$; F vs. prob, $P<0.001$; Fig. $8 \mathrm{D})$ and a sharply decreased $I L-10$ (mRNA level: control vs. F, $P=0.01$; F vs. prob, $P=0.02$; protein level: control vs. F, $P<0.001$; F vs. prob, $P<0.001$; Fig. $8 \mathrm{E}$ ) compared with the other two groups in mRNA and protein levels. These differences (IFN- $\gamma$ mRNA level: control vs. prob, $P=0.062 ; I L-10$ mRNA level: control vs. prob, $P=0.838 ; I L-10$ protein level: control vs. prob, $P=0.535$ ) were not observed in the other two groups except for $I F N-\gamma$ protein level (control vs. prob, $P=0.005$ ).

\section{Intestinal permeability}

As shown in Fig. 9A, the control group reported a slightly higher claudin-1 than the other two groups (control vs. F, $P=0.111$; control vs. prob, $P=0.129$ ). The mRNA expression of claudin- 1 between the $\mathrm{F}$ and prob groups had no difference (F vs. prob, $P=0.855$ ). Figure $9 \mathrm{~A}$ also shows that $Z O-1$ and occludin in the control group were remarkably higher than those in the $\mathrm{F}$ group $(P=0.008, P=0.004)$ and slightly $(P=0.121, P=0.061)$ higher than the prob group. Figure 9A shows that the prob group presented a slightly more $Z O-1(P=0.125)$ and occludin $(P=0.114)$ than the $\mathrm{F}$ group. Figure $9 \mathrm{~B}$ and $9 \mathrm{C}$ show that the $\mathrm{F}$ group exhibited a significant increase in serum DAO activity (control vs. F, $P=0.002$; F vs. prob, $P=0.048$ ) and D-lactate concentration (control vs. F, $P<0.001$; F vs. prob, $P=0.011$ ) compared with the other two groups. No significant $(P=0.128)$ difference in the DAO activity between the control and prob groups was 
326

327

328

329

330

331

332

333

334

335

336

337

338

339

340

341

342

343

344

345

346

347

348

349

350

351

352

353

354

355

356

357

358

observed. The D-lactate concentration in the prob group was significantly $(P=0.001)$ higher than that in the control group.

\section{Discussion}

Although a large number of studies have found fluoride-induced brain lesions, few studies focused on the link between the gut changes and neurotoxicity induced by fluoride. In view of the gut-brain axis, changes in the intestinal microenvironment, including gut microbiota, inflammatory cytokines, and hormones, can influence brain chemistry and behaviors. The current study further explored fluoride-induced brain lesion and its link with the gut. We found that the mice exposed to $100 \mathrm{mg} / \mathrm{L}$ sodium fluoride for 10 weeks had hippocampal lesions, which caused memory impairment as indicated by their lower performance in the T-maze test and the reduced PLP mRNA level. Moreover, high fluoride exposure caused intestinal inflammation and increased the intestinal permeability as indicated by the increased inflammatory cytokines, serum DAO activity, and D-lactate content and reduced mRNA levels of TJ protein. BS15, a probiotic capable of improving the gut microbiome, reversed the gut changes and alleviated the brain lesion and memory impairment induced by fluoride. The current study confirmed our hypothesis that gut changes may play a key role in memory dysfunction during high fluoride exposure, and BS15 administration is a potential method of preventing these fluoride-induced damages on memory ability.

Although the memory abilities of the three groups were not remarkably different as shown in the NOR test, the fluoride-infected mice in the F group showed memory impairment as indicated by their lower spontaneous exploration in the T-maze test compared with the other groups. The poor performances of the fluoride-infected mice in various memory-related behavioral tests were also reported in previous studies (Liu et al., 2010; Chen et al., 2018). In our study, BS15 substantially reversed the performance of mice in the T-maze and thus has a beneficial effect on the memory ability of fluoride-infected mice. Neuronal activation was also decreased as indicated by the lower mRNA level of $c$-fos in the hippocampus of fluoride-infected mice. Fleischmann et al. (2003) demonstrated that mice lacking $c$-fos exhibit remarkable memory deficits; hence, $c$-fos gene has a critical role in memory. The hippocampus is a unique area of the brain that is able of neuroplasticity (Galea et al., 2013). Neuroplasticity usually increases under the conditions that increase memory abilities, and its ablation often induces lesions that affect memory (Deng, Aimone \& Gage, 2010; Leuner \& Gould, 2010). These findings suggested that the hippocampus play a critical role in memory and synaptic plasticity (Yirmiya \& Goshen, 2011). Neurotrophic factors, especially the BDNF, are important in neurogenesis, and their production are involved in 
359

360

361

362

363

364

365

366

367

368

369

370

371

372

373

374

375

376

377

378

379

380

381

382

383

384

385

386

387

388

389

390

391

392

393

almost every aspect of neural and behavioral plasticity (Lu, Christian \& Lu, 2008; Li et al., 2008), especially for hippocampal-dependent memory (Heldt et al., 2007). An increasing body of data indicated that probiotic consumption can regulate anxiety and memory functions via changes in the expression of key components, such as $B D N F, C R E B$, and N-methyl-d-aspartate receptors (Clarke et al., 2013; Wall et al., 2010). The underlying mechanism is that probiotics can synthesize and recognize an array of neurochemicals, including neurotransmitters, secondary bile acids, neuroactive short chain fatty acids (SCFAs), and other biologically active small molecules. For example, Kumar et al. (2017) reported that L. johnsonii could increase the concentrations of acetate and butyrate in feces. Butyrate, an SCFA, can decrease $B D N F$ methylation and consequently cause an overexpression of $B D N F$ by decreasing ten-eleven translocation methylcytosine dioxygenase 1 , which is the enzyme responsible for catalyzing the conversion of DNA methylation to hydroxymethylation (Wei et al., 2015). In the present study, the expression of $B D N F$ in the hippocampus was reduced by fluoride. This finding is consistent with the result found by Niu et al. (2018) CREB is the transcriptional regulator of BDNF, and similar genomic network analysis reported that $C R E B$ is the center of Alzheimer's disease's pathology (Jeong et al., 2001). The mRNA and protein levels of BDNF and CREB in the BS15treated mice were substantially increased compared with the fluoride-infected mice, and the level of CREB was even slightly higher than the control group. Similarly, Kadry and Megeed (2018) found that Lactobacillus could effectively inhibit the reduction of BDNF induced by cadmium chloride in the hippocampus of mice. Moreover, Corpuz et al. (2018) reported that Lactobacillus paracase $\mathrm{K} 71$ prevents age-related cognitive decline in senescence-accelerated mouse prone 8 by increasing the protein expression of $B D N F$ and the phosphorylation of $C R E B$ in the hippocampus. Neuroplasticity also needs the regulation of NCAM (Seidenfaden, Krauter \& Hildebrandt, 2006) and the stimulation of SCF (Jin et al., 2002). In line with the results of Niu et al. (2018), fluoride significantly reduced the mRNA level of NCAM.

Many evidence indicated that neuroinflammation may be one of the pathogenesis underlying cognitive changes and the development of many neurodegenerative diseases (Frank-Cannon et al., 2009). The hippocampus is vulnerable to the insults by inflammatory cytokines because of its high expression of cytokine receptors (Das \& Research, 2008). Few in vivo studies focused on the neuroinflammation caused by fluorosis. Excessive exposure to fluoride triggered neuroinflammation as indicated by the increase in the $T N F-\alpha$ and $I F N-\gamma$ in the hippocampus of the F group. The result on TNF- $\alpha$ was in agreement with the finding of Yan et al. (2016), who found that $T N F-\alpha$ immunoreactivity is increased in the hippocampus of rat exposed to $120 \mathrm{ppm}$ fluoride for 10 weeks. However, by contrast to the results shown by Yan et al. (2016), the present study reported a reduced $I L-6$ in the hippocampus of mice exposed to $100 \mathrm{mg} / \mathrm{L}$ sodium fluoride

Peer] reviewing PDF | (2020:02:46283:3:0:CHECK 4 Sep 2020) 
394 for 10 weeks. Differences in drug doses, delivery cycles, and breeds of rodents may be

395 associated with the contradictory results. A previous research confirmed that $I L$ - 6 -deficient mice 396 present a weakened neuroprotection of the hippocampus (Jean Harry, Bruccoleri \& Lefebvre 397 d'Hellencourt, 2003). Funk et al. (2011) indicated the potential role of IL-6 in modulating TNF$\alpha$-mediated neurotoxicity. Intestinal microbiome and some probiotics can influence health status and disease risk by activating immune response against dangerous stimuli and activating regulatory mechanisms to avoid uncontrolled inflammation. Intestinal permeability and potentially beneficial metabolites may be the underlying mechanisms of the anti-inflammation. Intestinal microbiome can ferment dietary fiber and starch in the large intestines and produce SCFAs (Chen, Faller \& Spanjaard, 2003). The effect of butyrate and other SCFAs on preventing inflammation in colon diseases and different neural inflammation models in cell cultures have been demonstrated (Huuskonen, 2004). In the present study, BS15 administration had profitable effect on balancing the inflammatory cytokines in fluoride-infected mice.

The mRNA expression levels of myelin- and apoptosis-related proteins were also detected to further investigate the effect of BS15 on the hippocampal impairment. Myelin sheaths enwrap the nerve fiber to guarantee interneuronal transmission efficiency (Nguyen et al., 2009). Myelin is consisted of $P L P$ (a transmembrane protein), $M B P$ (a peripheral membrane protein), the outermost $M O G$, and the innermost $M A G$ (Niu et al., 2018). The remarkably reduced mRNA expression levels of PLP and $M O G$ in the F group suggested that myelin lesion occurred in the hippocampus. The changes in PLP induced by fluoride were consistent with the findings of Niu et al. (2018). The reduced tendency of PLP was inhibited by BS15; hence, BS15 may have a protective effect on the myelin. A previous study demonstrated that mice present increased positive apoptotic neurons following 10 weeks of exposure to $120 \mathrm{ppm}$ fluoride in drinking water (Yan et al., 2016). In the present study, the reduced Bcl-2 (anti-apoptosis protein) and increased caspase-3 (pro-apoptosis protein) in fluoride-infected mice created conditions for apoptotic neurons, and these changes were remarkably reversed by BS15 treatment.

Intestinal leakage can facilitate the translocation of bacterial composition, such as microorganisms and their products (Carvalho AF, Berk M\& Maes M 2016), and is considered a key factor in mental disease (Braniste et al., 2014; Zhan et al., 2016; Emery et al., 2017). Inflammation can enhance epithelial permeability (Xue et al., 2014; Schulzke et al., 2009). Inflammatory cytokines, such as $I L-1 \beta, T N F-\alpha$, and $I F N-\gamma$, can increase gut permeability (Ma et al., 2004; Schulzke et al., 2009; Weber et al., 2010). IL-10, an anti-inflammatory cytokine, plays a critical role in the homeostasis of the gut, which was illustrated by the finding that spontaneous colitis occurs in $I L-10^{-1-}$ mice (Gomes-Santos et al., 2012). The current study found that excessive fluoride intake resulted in intestinal inflammation by increasing pro-inflammatory 
429 cytokines $(T N F-\alpha, I L-1 \beta$, and $I F N-\gamma)$ and reducing anti-inflammatory cytokine $(I L-10)$.

430 Treatment with BS15 efficiently lowered the inflammatory reaction caused by fluoride. TJ

431 proteins act as a barrier that mediates the cell-to-cell adhesion and prevents molecules from

432 crossing through the epithelial sheet between adjacent cells into systemic circulation (Piche,

433 2014). The mRNA level of two TJ proteins, namely, ZO-1 and occludin, in the ileum of the

434 fluoride-infected mice were also remarkably reduced with gut inflammation enhancement and

435 therefore led to higher levels of DAO activity and D-lactate content in the serum. The tissue of

436 the small intestine contains the highest DAO activity, and serum DAO is derived primarily from

437 the small intestines in many mammalian species (Luk, Bayless \& Baylin, 1980). Moreover,

438 mammalian species cannot produce D-lactate, and the main source of D-lactate is from the

439 commensal bacteria in the gastrointestinal tract (Sun et al, 2001). The metabolism of serum D-

440 lactate is very slow. The increases in serum DAO activity and D-lactate content occurred when

441 the intestinal mucosal integrity was damaged and served as useful plasma markers of mucosal

442 integrity (Ewaschuk, Naylor \& Zello, 2005; Luk, Bayless \& Baylin, 1980). In this study, we

443 found that BS15 effectively improved intestinal permeability as shown by the remarkably lower

444 serum DAO activity and D-lactate concentration in the prob group compared with the F group.

445 The result may be explained in part by the slightly increased TJ proteins in the prob group.

446 Apoptosis is another possible reason that may have caused barrier dysfunction (Schulzke et al.,

447 2009). These results suggested that fluoride could cause intestinal inflammation and damage

448 mucosal integrity, which results in enhanced intestinal permeability, and BS15 administration

449 could alleviate these pathological changes.

450 Conclusions

451 The study deepened our understanding of the link between fluoride neurotoxicity on memory

452 function and gut microenvironment. BS15 exerted beneficial effects against excessive fluoride

453 intake-induced memory impairment, related neural inflammation, and demyelination by

454 improving intestinal inflammation and integrity and increasing apoptosis markers in the

455 hippocampus of mice.

456

457 Acknowledgments

458 The present study was supported by the National Natural Science Foundation of China (NSFC)

459 grant numbers (31970503). The authors gratefully acknowledge the help from Ms. Peng Xueji

Peer) reviewing PDF | (2020:02:46283:3:0:CHECK 4 Sep 2020) 
460

461

462

463

464

465

466

467

468

469

470

471

472

473

474

475

476

477

478

and Mr. Zhang Shuai for all the hard working during the behavioral tests. Also, we really appreciate the supports provided by all other undergraduates during the animal feeding and sampling.

\section{References}

Antunes M, Biala G. 2012. The novel object recognition memory: neurobiology, test procedure, and its modifications. Cogn Process 13(2):93-110 DOI: 10.1007/s10339-011-0430-z.

Arentsen T, Raith H, Qian Y, Forssberg H, Heijtz RD. 2015. Host microbiota modulates development of social preference in mice. Microb Ecol Health Dis 26:29719 DOI: 10.3402/mehd.v26.29719.

Bashash M, Thomas D, Hu H, Martinez-Mier EA, Sanchez BN, Basu N, Peterson KE, Ettinger AS, Wright R, Zhang Z, Liu Y, Schnaas L, Mercado-García A, Téllez-Rojo MM, HernándezAvila M. 2017. Prenatal fluoride exposure and cognitive outcomes in children at 4 and 6-12 years of age in mexico. Environ Health Perspect 125(9): 097017 DOI: 10.1289/EHP655.

Bercik P, Denou E, Collins J, Jackson W, Lu J, Jury J, Deng Y, Blennerhassett P, Macri J, McCoy KD, Verdu EF, Collins SM. 2011. The intestinal microbiota affect central levels of brain-derived neurotropic factor and behavior in mice. Gastroenterology 141(2):599-609, 609.e1-3 DOI: 10.1053/j.gastro.2011.04.052.

Braniste V, Al-Asmakh M, Kowal C, Anuar F, Abbaspour A, Tóth M, Korecka A, Bakocevic N, Ng LG, Kundu P, Gulyás B, Halldin C, Hultenby K, Nilsson H, Hebert H, Volpe BT, Diamond B, Pettersson S. 2014. The gut microbiota influences blood-brain barrier permeability in mice. Sci Transl Med 6(263): 263ra158. DOI: 10.1126/scitranslmed.3009759.

Carvalho AF, Berk M, Maes M. 2016. Editorial: Gut permeability and the microbiome: emerging roles in CNS function in health and disease. Curr Pharm Des. Epub ahead of print.

Chen L, Ning H, Yin Z, Song X, Tao R, Hua L, Liu J, Wang J, Ning H. 2018. Fluoride-induced alterations of synapse-related proteins in the cerebral cortex of ICR offspring mouse brain.

Chemosphere 201:874-883 DOI: 10.1016/j.chemosphere.2018.02.167.

Chen JS, Faller DV, Spanjaard RA. 2003. Short-chain fatty acid inhibitors of histone deacetylases: promising anticancer therapeutics. Curr Cancer Drug Targets 3(3):219-36. DOI:

Peer) reviewing PDF | (2020:02:46283:3:0:CHECK 4 Sep 2020) 
489

490

491

492

493

494

495

496

497

498

499

500

501

502

503

504

505

506

507

508

509

510

511

$10.2174 / 1568009033481994$.

Corpuz HM, Ichikawa S, Arimura M, Mihara T, Kumagai T, Mitani T, Nakamura S, Katayama S. (2018) Long-term diet supplementation with Lactobacillus paracasei K71 prevents age-related cognitive decline in senescence-accelerated mouse prone 8. Nutrients 10(6): pii: E762. DOI: 10.3390/nu10060762.

Clarke, G. Grenham, S. Scully, P. Fitzgerald, P. Moloney, R. D. Shanahan, F. Dinan, T. G. Cryan, J. F. 2013. The microbiome-gut-brain axis during early life regulates the hippocampal serotonergic system in a sex-dependent manner. Mol Psychiatry 18(6):666-673. DOI: 10.1038/mp.2012.77.

Czerwiński E, Lankosz W. 1978. Fluoride-induced changes in the locomotor system in 60 retired workers of an aluminum plant. Chir Narzadow Ruchu Ortop Pol 43(2):149-56.

Das S, Research A. 2008. Inflammation: A new candidate in modulating adult neurogenesis. $J$ Neurosci Res 86(9):1199-1208 DOI: 10.1002/jnr.21585.

Desbonnet L, Clarke G, Shanahan F, Dinan TG, Cryan JF. 2014. Microbiota is essential for social development in the mouse. Mol Psychiatry 19(2):146-8 DOI: 10.1038/mp.2013.65.

Deacon RM, Rawlins JN. 2006. T-maze alternation in the rodent. Nat Protoc 1(1):7-12 DOI: 10.1038/nprot.2006.2.

Deisseroth K, Tsien RW. 2002. Dynamic multiphosphorylation passwords for activity-dependent gene expression. Neuron 34(2):179-182 DOI: 10.1016/s0896-6273(02)00664-5.

Deng W, Aimone JB, Gage FH. 2010. New neurons and new memories: how does adult hippocampalneuroplasticityaffect learning and memory? Nat Rev Neurosci 11(5):339-50 DOI: $10.1038 / \mathrm{nrn} 2822$.

Emery DC, Shoemark DK, Batstone TE, Waterfall CM, Coghill JA, Cerajewska TL, Davies M, West NX, Allen SJ. 2017. 16S rRNA next generation sequencing analysis shows bacteria in Alzheimer's post-mortem brain. Front Aging Neurosci 9:195 DOI: 10.3389/fnagi.2017.00195.

Ewaschuk JB, Naylor JM, Zello GA. 2005. D-lactate in human and ruminant metabolism. J Nutr 135(7):1619-1625 DOI: 10.1093/jn/135.7.1619.

Fleischmann A, Hvalby O, Jensen V, Strekalova T, Zacher C, Layer LE, Kvello A, Reschke M, Spanagel R, Sprengel R, Wagner EF, Gass P. 2003. Impaired long-term memory and NR2AType NMDA receptor-dependent synaptic plasticity in mice lacking c-Fos in the CNS. $J$ 
519

520

521

522

523

524

525

526

527

528

529

530

531

532

533

534

535

536

537

538

539

540

541

542

543

544

545

546

547

548

Neurosci 23:9116-9122.

Littleton J. 1999. Paleopathology of skeletal fluorosis. Am J Phys Anthropol 109(4):465-483

DOI: 10.1002/(SICI)1096-8644(199908)109:4<465::AID-AJPA4>3.0.CO;2-T.

Forsythe P, Kunze WA. 2013. Voices from within: gut microbes and the CNS. Cell Mol Life Sci 70(1):55-69 DOI: 10.1007/s00018-012-1028-z.

Frank-Cannon TC, Alto LT, Mcalpine FE, Tansey MG. 2009. Does neuroinflammation fan the flame in neurodegenerative diseases? Mol Neurodegener 4:47 DOI: 10.1186/1750-1326-4-47.

Fung KF, Zhang ZQ, Wong JWC, Wong MH. 1999. Fluoride contents in tea and soil from tea plantations and the release of fluoride into tea liquor during infusion. Environ Pollut 104:197205 DOI: org/10.1016/S0269-7491(98)00187-0.

Funk JA, Gohlke J, Kraft AD, McPherson CA, Collins JB, Jean Harry G. 2011. Voluntary exercise protects hippocampal neurons from trimethyltin injury: Possible role of interleukin-6 to modulate tumor necrosis factor receptor-mediated neurotoxicity. Brain Behav Immun 25(6):1063-77 DOI: 10.1016/j.bbi.2011.03.012. Epub 2011 Mar 22.

Galea LAM, Wainwright SR, Roes MM, Duarte-Guterman P, Chow C, Hamson DK. 2013. Sex, hormones and neurogenesis in the hippocampus: hormonal modulation of neurogenesis and potential functional implications. J Neuroendocrinol 25(11):1039-61 DOI: 10.1111/jne.12070.

Gareau MG, Wine E, Rodrigues DM, Cho JH, Whary MT, Philpott DJ, Macqueen G, Sherman PM. 2011. Bacterial infection causes stress-induced memory dysfunction in mice. Gut 60(3): 307-317 DOI: 10.1136/gut.2009.202515.

Gomes-Santos AC, Moreira TG, Castro-Junior AB, Horta BC, Lemos L, Cruz DN, Guimarães MA, Cara DC, McCafferty DM, Faria AM. 2012. New insights into the immunological changes in IL-10-deficient mice during the course of spontaneous inflammation in the gut mucosa. Clin Dev Immunol 2012:560817. DOI: 10.1155/2012/560817.

Greenberg ME, Ziff EB, Greene LA. 1986. Stimulation of neuronal acetylcholine receptors induces rapid gene transcription. Science 234:80-83. DOI: 10.1126/science.3749894.

Heldt SA, Stanek L, Chhatwal JP, Ressler KJ. 2007. Hippocampus-specific deletion of $B D N F$ in adult mice impairs spatial memory and extinction of aversive memories. Mol Psychiatry 12(7):656-670 DOI: 10.1038/sj.mp.4001957.

Hong EJ, Mccord AE, Greenberg ME. 2008. A biological function for the neuronal activity- 
549 dependent component of Bdnf transcription in the development of cortical inhibition. Neuron 550 60(4):610-624 DOI: 10.1016/j.neuron.2008.09.024.

551 Huuskonen J, Suuronen T, Nuutinen T, Kyrylenko S, Salminen A. (2004) Regulation of 552 microglial inflammatory response by sodium butyrate and short-chain fatty acids. $\mathrm{Br} J$ 553 Pharmacol 141(5):874-80. DOI: 10.1038/sj.bjp.0705682.

554 Jaini R, Kesaraju P, Johnson JM, Altuntas CZ, Janewit D, Tuohy VK. 2010. Prophylactic breast 555 cancer vaccination. Nat Med 16(7):799-803 DOI:10.1038/nm.2161.

556 Jean Harry G, Bruccoleri A, Lefebvre d'Hellencourt C. 2003. Differential modulation of 557 hippocampal chemical-induced injury response by ebselen, pentoxifylline, and $T N F \alpha-, I L-1 \alpha-$, 558 and IL-6-neutralizing antibodies. J Neurosci Res 73(4): 526-36 DOI: 10.1002/jnr.10653.

559 Jeong H, Mason SP, Barabasi AL, Oltvai ZN. 2001. Lethality and centrality in protein networks. 560 Nature 411(6833):41-42 DOI: 10.1038/35075138.

Jin K, Mao XO, Sun Y, Xie L, Greenberg DA. 2002. Stem cell factor stimulates neurogenesis in vitro and in vivo. J Clin Invest 110(3):311-319 DOI: 10.1172/JCI15251

Kadry MO, Megeed RA. (2018) Probiotics as a complementary therapy in the model of cadmium chloride toxicity: crosstalk of $\beta$-Catenin, BDNF, and StAR signaling pathways. Biol Trace Elem Res 185(2):404-413. DOI: 10.1007/s12011-018-1261-x.

Kumar S, Pattanaik AK, Sharma S, Jadhav SE, Dutta N, Kumar A. 2017. Probiotic potential of a Lactobacillus Bacterium of canine faecal-origin and its impact on select gut health indices and immune response of dogs. Probiotics Antimicrob Proteins 9(3):262-277. DOI: 10.1007/s12602017-9256-z.

Leuner B, Gould E. 2010. Structural plasticity and hippocampal function. Annu Rev Psychol 61:111-140, c111-113 DOI: 10.1146/annurev.psych.093008.100359

Liu YJ, Gao Q, Wu CX, Guan ZZ. 2010. Alterations of $n A C h R s$ and ERK1/2 in the brains of rats with chronic fluorosis and their connections with the decreased capacity of learning and memory. Toxicol Lett 192(3):324-329 DOI: 10.1016/j.toxlet.2009.11.002.

Li Y, Luikart BW, Birnbaum S, Chen J, Kwon CH, Kernie SG, Basselduby R, Parada LF. 2008. $\operatorname{TrkB}$ regulates hippocampal neurogenesis and governs sensitivity to antidepressive treatment. Neuron 59(3):399-412 DOI: 10.1016/j.neuron.2008.06.023.

8 Lu Y, Christian K, Lu B. 2008. BDNF: A key regulator for protein-synthesis dependent LTP and 
579

580

581

582

583

584

585

586

587

588

589

590

591

592

593

594

595

596

597

598

599

600

601

602

603

604

605

606

607

608

long-term memory? Neurobiol Learn Mem 89(3):312-323 DOI: 10.1016/j.nlm.2007.08.018.

Luk GD, Bayless TM, Baylin SB. 1980. Diamine oxidase (histaminase). a circulating marker for rat intestinal mucosal maturation and integrity. J Clin Invest 66(1):66-70 DOI: 10.1172/JCI109836.

Luo Q, Cui H, Peng X, Fang J, Zuo Z, Deng J, Liu J, Deng Y. 2016. Dietary high fluorine alters intestinal microbiota in broiler chickens. Biol Trace Elem Res 173(2):483-91 DOI: 10.1007/s12011-016-0672-9.

Ma TY, Iwamoto GK, Hoa NT, Akotia V, Pedram A, Boivin MA, Said HM. 2004. TNF-alphainduced increase in intestinal epithelial tight junction permeability requires $N F$-kappa $B$ activation. Am J Physiol Gastrointest Liver Physiol 286(3):G367-76 DOI: 10.1152/ajpgi.00173.2003.

Maienfisch P, Hall RG. 2004. The importance of fluorine in the life science industry. Chimia 58:93-99.

Mantamadiotis T, Lemberger T, Bleckmann SC, Kern H, Kretz O, Villalba AM, Tronche Fo, Kellendonk C, Gau D, Kapfhammer J, Otto C, Schmid W, Schütz G. 2002. Disruption of CREB function in brain leads to neurodegeneration. Nat Genet 31(1):47-54. DOI: 10.1038/ng882.

Mayer EA. 2011. Gut feelings: the emerging biology of gut-brain communication. Nat Rev Neurosci 12(8):453-466 DOI: 10.1038/nrn3071.

Nguyen T, Mehta NR, Conant K, Kim KJ, Jones M, Calabresi PA, Melli G, Hoke A, Schnaar RL, Ming GL, Song H, Keswani SC, Griffin JW. 2009. Axonal protective effects of the myelinassociated glycoprotein. J Neurosci 29(3):630-637 DOI: 10.1523/JNEUROSCI.5204-08.2009.

Niu R, Chen H, Manthari RK, Sun Z, Wang J, Zhang J, Wang J. 2018. Effects of fluoride on synapse morphology and myelin damage in mouse hippocampus. Chemosphere 194:628-633 DOI: 10.1016/j.chemosphere.2017.12.027.

Petrone P, Guarino FM, Giustino S, Gombos F. 2013. Ancient and recent evidence of endemic fluorosis in the naples area. J Geochem Explor 131:14-27 DOI: 10.1016/j.gexplo.2012.11.012.

Piche T. 2014. Tight junctions and IBS - the link between epithelial permeability, low-grade inflammation, and symptom generation? Neurogastroenterol Motil 26(3):296-302 DOI: 10.1111/nmo.12315.

Razdan P, Patthi B, Kumar JK, Agnihotri N, Chaudhari P, Prasad M. 2017. Effect of fluoride 
609 concentration in drinking water on intelligence quotient of 12-14-year-old children in mathura 610 district: A cross-sectional study. J Int Soc Prev Community Dent 7(5):252-258 DOI:

611 10.4103/jispcd.JISPCD_201_17.

612 Ren W, Liu S, Chen S, Zhang F, Li N, Yin J, Peng Y, Wu L, Liu G, Yin Y, Wu G. 2013. Dietary 613 L-glutamine supplementation increases pasteurella multocida burden and the expression of its 614 major virulence factors in mice. Amino Acids 45(4):947-955 DOI: 10.1007/s00726-013-1551-8.

615 Sabokseir A, Golkari A, Sheiham A. 2016. Distinguishing between enamel fluorosis and other 616 enamel defects in permanent teeth of children. PeerJ 4: e1745 DOI: 10.7717/peerj.1745.

617 Schulzke JD, Ploeger S, Amasheh M, Fromm A, Fromm M. 2009. Epithelial tight junctions in 618 intestinal inflammation. Ann N Y Acad Sci 1165:294-300 DOI: 10.1111/j.1749-

619 6632.2009.04062.x.

620 Sebastian ST, Sunitha S. 2015. A cross-sectional study to assess the intelligence quotient (IQ) of 621 school going children aged 10-12 years in villages of mysore district, india with different 622 fluoride levels. J Indian Soc Pedod Prev Dent 33(4):307-311 DOI: 10.4103/0970-4388.165682.

623 Seidenfaden R, Krauter A, Hildebrandt H. 2006. The neural cell adhesion molecule NCAM 624 regulates neurogenesis by multiple mechanisms of interaction. Neurochem Int 49(1):1-11 DOI: 625 10.1016/j.neuint.2005.12.011.

626 Simpson CS, Morris BJ. 2000. Regulation of neuronal cell adhesion molecule expression by $N F$ 627 kappa B. J Biol Chem 275(22):16879-84 DOI: 10.1074/jbc.275.22.16879.

628 Sgritta M, Dooling SW, Buffington SA, Momin EN, Francis MB, Britton RA, Costa-Mattioli M. 629 2019. Mechanisms Underlying Microbial-Mediated Changes in Social Behavior in Mouse 630 Models of Autism Spectrum Disorder. Neuron 101(2)246-259.e6 DOI:

631 10.1016/j.neuron.2018.11.018.

632 Sun XQ, Fu XB, Zhang R, Lu Y, Deng Q, Jiang XG, Sheng ZY. (2001) Relationship between 633 plasma $\mathrm{D}(-)$-lactate and intestinal damage after severe injuries in rats. World J Gastroenterol 634 7(4):555-8. DOI: 10.3748/wjg.v7.i4.555.

635 Stachenfeld KL, Botvinick MM, Gershman SJ. 2017 The hippocampus as a predictive map. Nat 636 Neurosci 20(11):1643-1653. doi: 10.1038/nn.4650.

637 Wang SX, Wang ZH, Cheng XT, Li J, Sang ZP, Zhang XD, Han LL, Qiao XY, Wu ZM, Wang 638 ZQ. 2007. Arsenic and fluoride exposure in drinking water: Children's IQ and growth in Shanyin 
639

640

641

642

643

644

county, Shanxi province, China. Environ Health Perspect 115(4):643-647. DOI: 10.1289/ehp.9270

Wang Z, Rong W, Zhang Y, Zeng X, Li Z, Liu Z. 2019. Prevalence and contributing factors of dental caries of 6-year-old children in four regions of China. PeerJ 7:e6997 DOI: 10.7717 peerj.6997.

Wall R, Ross RP, Shanahan F, O'Mahony L, Kiely B, Quigley E, Dinan TG, Fitzgerald G, Stanton C. 2010. Impact of administered bifidobacterium on murine host fatty acid composition. Lipids 45(5):429-36. DOI: 10.1007/s11745-010-3410-7.

Wei YB, Melas PA, Wegener G, Mathé AA, Lavebratt C. (2015) Antidepressant-like effect of sodium butyrate is associated with an increase in TET1 and in 5-hydroxy- methylation levels in the bdnf gene. Int J Neuropsychopharmacol 18(2). pii: pyu032. DOI: 10.1093/ijnp/pyu032.

Weber CR, Raleigh DR, Su L, Shen L, Sullivan EA, Wang Y, Turner JR. 2010. Epithelial myosin light chain kinase activation induces mucosal interleukin-13 expression to alter tight junction ion selectivity. J Biol Chem 285:12037-12046.

Qian W, Miao K, Li T, Zhang Z. 2013. Effect of selenium on fluoride-induced changes in synaptic plasticity in rat hippocampus. Biol Trace Elem Res 155(2):253-260 DOI: 10.1007/s12011-013-9773-x.

Xin JG, Zeng D, Wang HS, Ni XQ, Yi D, Pan KC, Jing B. 2014. Preventing non-alcoholic fatty liver disease through Lactobacillus johnsonii BS15 by attenuating inflammation and mitochondrial injury and improving gut environment in obese mice. Appl Microbiol Biot 98(15):6817-29 DOI: 10.1007/s00253-014-5752-1.

Xue Y, Wang H, Du M, Zhu MJ. 2014. Maternal obesity induces gut inflammation and impairs gut epithelial barrier function in nonobese diabetic mice. J Nutr Biochem 25(7):758-764. DOI: 10.1016/j.jnutbio.2014.03.009.

Yasuda K, Hsu T, Gallini CA, Mclver LJ, Schwager E, Shi A, Dulong CR, Schwager RN, AbuAli GS, Franzosa EA, Garrett WS, Huttenhower C, Morgan XC. 2017. Fluoride depletes acidogenic taxa in oral but not gut microbial communities in mice. mSystems 2(4):e00047-17 DOI: $10.1128 / \mathrm{mSystems.00047-17.}$

Yan N, Liu Y, Liu S, Cao S, Wang F, Wang Z, Xi S. 2016. Fluoride-induced neuron apoptosis and expressions of inflammatory factors by activating microglia in rat brain. Mol Neurobiol 53(7):4449-4460 DOI: 10.1007/s12035-015-9380-2. 
670 Yirmiya R, Goshen I. 2011. Immune modulation of learning, memory, neural plasticity and 671 neurogenesis. Brain Behav Immun 25(2):181-213 DOI: 10.1016/j.bbi.2010.10.015.

672 Zhan X, Stamova B, Jin LW, Decarli C, Phinney B, Sharp FR. 2016. Gram-negative bacterial 673 molecules associate with Alzheimer disease pathology. Neurology 87(22):2324-2332 DOI: 674 10.1212/WNL.0000000000003391.

675 Zhong W, Zhao Y, McClain CJ, Kang YJ, Zhou Z. 2010. Inactivation of hepatocyte nuclear 676 factor-42 mediates alcohol-induced downregulation of intestinal tight junction proteins. Am J 677 Physiol Gastrointest Liver Physiol 299(3):1251-1254 DOI: 10.1152/ajpgi.00515.2009.

678

679

680 


\section{Table 1 (on next page)}

Primer sequences for the targeted mouse genes.

a The primer sequences of c-fos is designed by National Center for Biotechnology Information (NCBI) and the referenced gene ID is 14281. 
1 Table 1 Primer sequences for the targeted mouse genes

\begin{tabular}{|c|c|c|c|}
\hline & Primer sequences $\left(5^{\prime} \rightarrow 3^{\prime}\right)$ & Annealing temp $\left({ }^{\circ} \mathrm{C}\right)$ & Reference \\
\hline b-actin & $\begin{array}{l}\text { Forward: gctcttttccagccttcctt } \\
\text { Reverse: gatgtcaacgtcacactt }\end{array}$ & 60 & (Niu et al., 2018) \\
\hline BDNF & $\begin{array}{l}\text { Forward:gcgcccatgaaagaagtaaa } \\
\text { Reverse: tcgtcagacctctcgaacct }\end{array}$ & 60 & (Niu et al., 2018) \\
\hline NCAM & $\begin{array}{l}\text { Forward: gggaactccatcaaggtgaa } \\
\text { Reverse: ttgagcatgacgtggacact }\end{array}$ & 60 & (Niu et al., 2018) \\
\hline SCF & $\begin{array}{l}\text { Forward:ccttatgaagaagacacaaacttgg } \\
\text { Reverse:ccatcccggcgacatagttgaggg }\end{array}$ & 60 & (Niu et al., 2018) \\
\hline CREB & $\begin{array}{l}\text { Forward: ccagttgcaaacatcagtgg } \\
\text { Reverse: ttgtgggcatgaagcagtag }\end{array}$ & 60 & (Niu et al., 2018) \\
\hline MOG & $\begin{array}{l}\text { Forward: aaaacaccctgtggtgaagg } \\
\text { Reverse: atcctggttggcagaatcac }\end{array}$ & 60 & (Niu et al., 2018) \\
\hline MAG & $\begin{array}{l}\text { Forward: gttcctcagctcctcattgc } \\
\text { Reverse: ttggggatgtctcctgattc }\end{array}$ & 60 & (Niu et al., 2018) \\
\hline MBP & $\begin{array}{l}\text { Forward: atccaagtacctggccacag } \\
\text { Reverse: cctgtcaccgctaaagaagc }\end{array}$ & 60 & (Niu et al., 2018) \\
\hline PLP & $\begin{array}{l}\text { Forward: caggctcctgctagaaatgg } \\
\text { Reverse: ggtcttcaggagatgcttgc }\end{array}$ & 60 & (Niu et al., 2018) \\
\hline$c-f^{a}{ }^{a}$ & $\begin{array}{l}\text { Forward:cagagcgggaatggtgaaga } \\
\text { Reverse:ctgtctccgcttggagtgta }\end{array}$ & 59.5 & \\
\hline TNF- $\alpha$ & $\begin{array}{l}\text { Forward:acggcatggatctcaaagac } \\
\text { Reverse:agatagcaaatcggctgacg }\end{array}$ & 60 & (Xin et al., 2014) \\
\hline
\end{tabular}




\begin{tabular}{|c|c|c|c|}
\hline IL-1 $\beta$ & $\begin{array}{l}\text { Forward:atgaaagacggcacccac } \\
\text { Reverse:gcttgtgctctgcttgtgag }\end{array}$ & 60 & (Ren et al., 2013) \\
\hline IL-6 & $\begin{array}{l}\text { Forward:tgcaagagacttccatccagt } \\
\text { Reverse:gtgaagtagggaaggccg }\end{array}$ & 60 & (Ren et al., 2013) \\
\hline IL-10 & $\begin{array}{l}\text { Forward:ggttgccaagcettatcgga } \\
\text { Reverse:acctgctccactgccttgct }\end{array}$ & 60 & (Jaini et al., 2010) \\
\hline IFN- $\gamma$ & $\begin{array}{c}\text { Forward:tcaagtggcatagatgtggaagaa } \\
\text { Reverse:tggctctgcaggattttcatg }\end{array}$ & 60 & (Jaini et al., 2010) \\
\hline $\mathrm{ZO}-1$ & $\begin{array}{l}\text { Forward: gatccctgtaagtcacccaga } \\
\text { Reverse: ctccetgcttgcactcctatc }\end{array}$ & 60 & (Zhong et al., 2010) \\
\hline Claudin-1 & $\begin{array}{l}\text { Forward: ggggacaacatcgtgaccg } \\
\text { Reverse: aggagtcgaagactttgcact }\end{array}$ & 60 & (Zhong et al., 2010) \\
\hline Occludin & $\begin{array}{l}\text { Forward: ttgaaagtccacctccttacaga } \\
\text { Reverse: ccggataaaaagagtacgctgg }\end{array}$ & 60 & (Zhong et al., 2010) \\
\hline
\end{tabular}

2 a The primer sequences of c-fos is designed by National Center for Biotechnology Information 3 (NCBI) and the referenced gene ID is 14281. 
Figure 1

Results of behavioral tests.

(A) T-Maze and (B) NOR preference tests. Data are presented as mean \pm standard deviation (T-maze, $n=8$; NOR, $n=10)$. Bars with different letters $(a, b$, and $c)$ indicate significant difference on the basis of Duncan's multiple range test $(P<0.05)$.
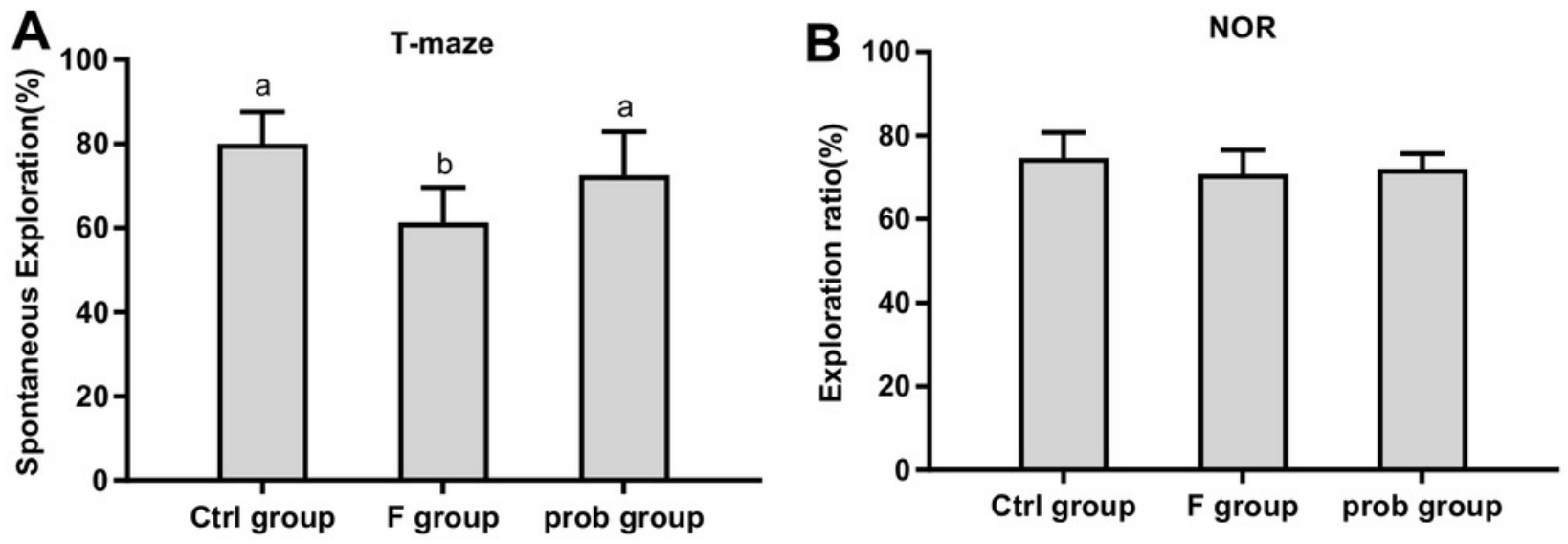


\section{Figure 2}

BDNF expression in the hippocampus of mice.

(A) mRNA expression level of BDNF in the hippocampus(n=4-5). (B-D) The images labeled $B, C$, and $D$ present results of immunohistochemistry in control, $F$, and prob groups, respectively $(n=3)$. (E) Results of $B D N F$ immunohistochemistry were quantified, and the results are presented in the figure 2E. The BDNFpositive cells are brown. Data are presented as mean \pm standard deviation. Bars with different letters $(a, b$, and $c)$ indicate significant difference on the basis of Duncan's multiple range test $(P<0.05)$. DG: dentategyrus.

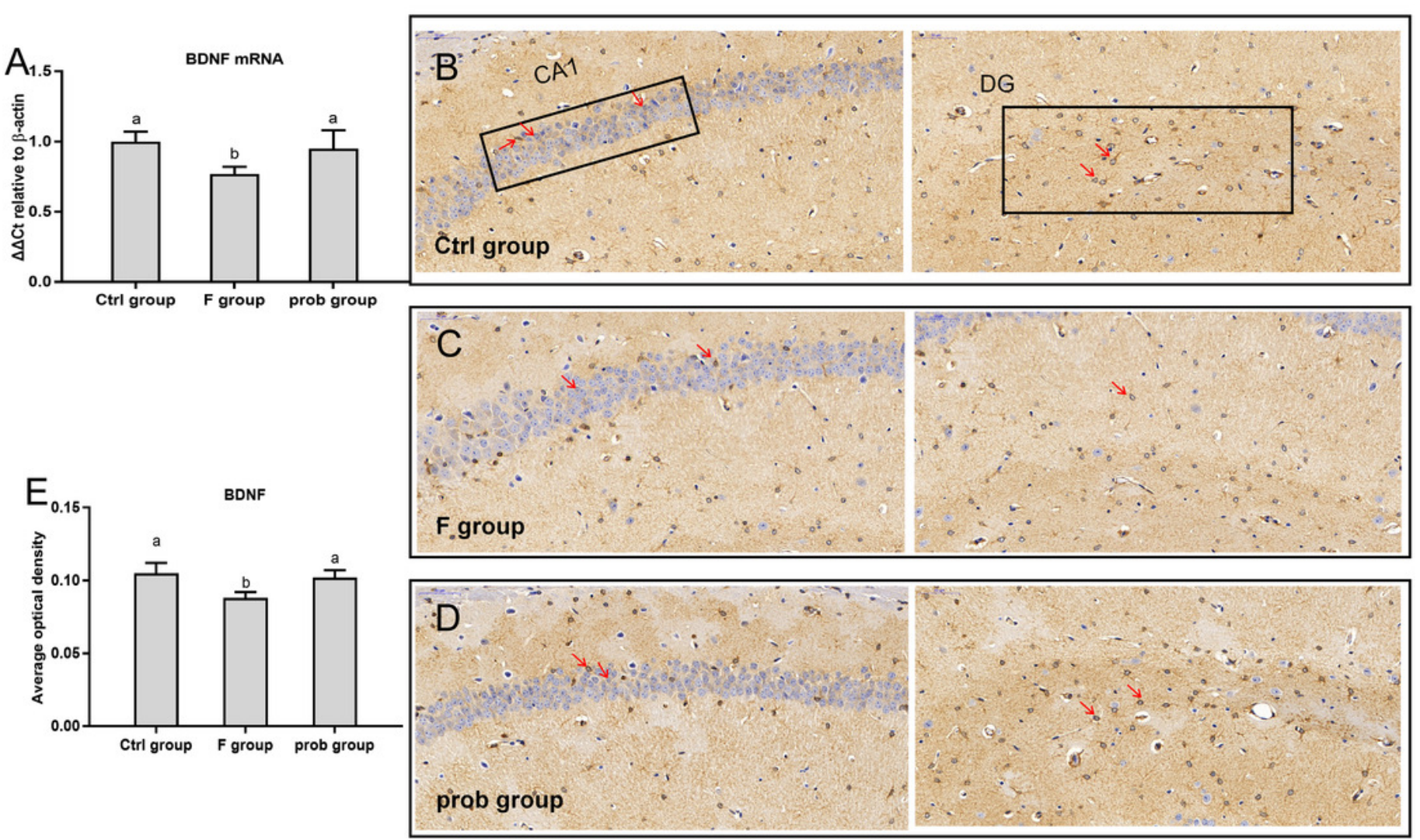




\section{Figure 3}

CREB expression in the hippocampus of mice.

(A) mRNA expression level of CREB in the hippocampus(n=4-5). (B-D) The images labeled $B, C$, and $D$ present results of immunohistochemistry in control, $F$, and prob groups, respectively $(n=3)$. (E) Results of CREB immunohistochemistry were quantified, and the results are presented in the figure 2E. The CREBpositive cells are brown. Data are presented as mean \pm standard deviation. Bars with different letters $(a, b$, and $c)$ indicate significant difference on the basis of Duncan's multiple range test $(P<0.05)$.
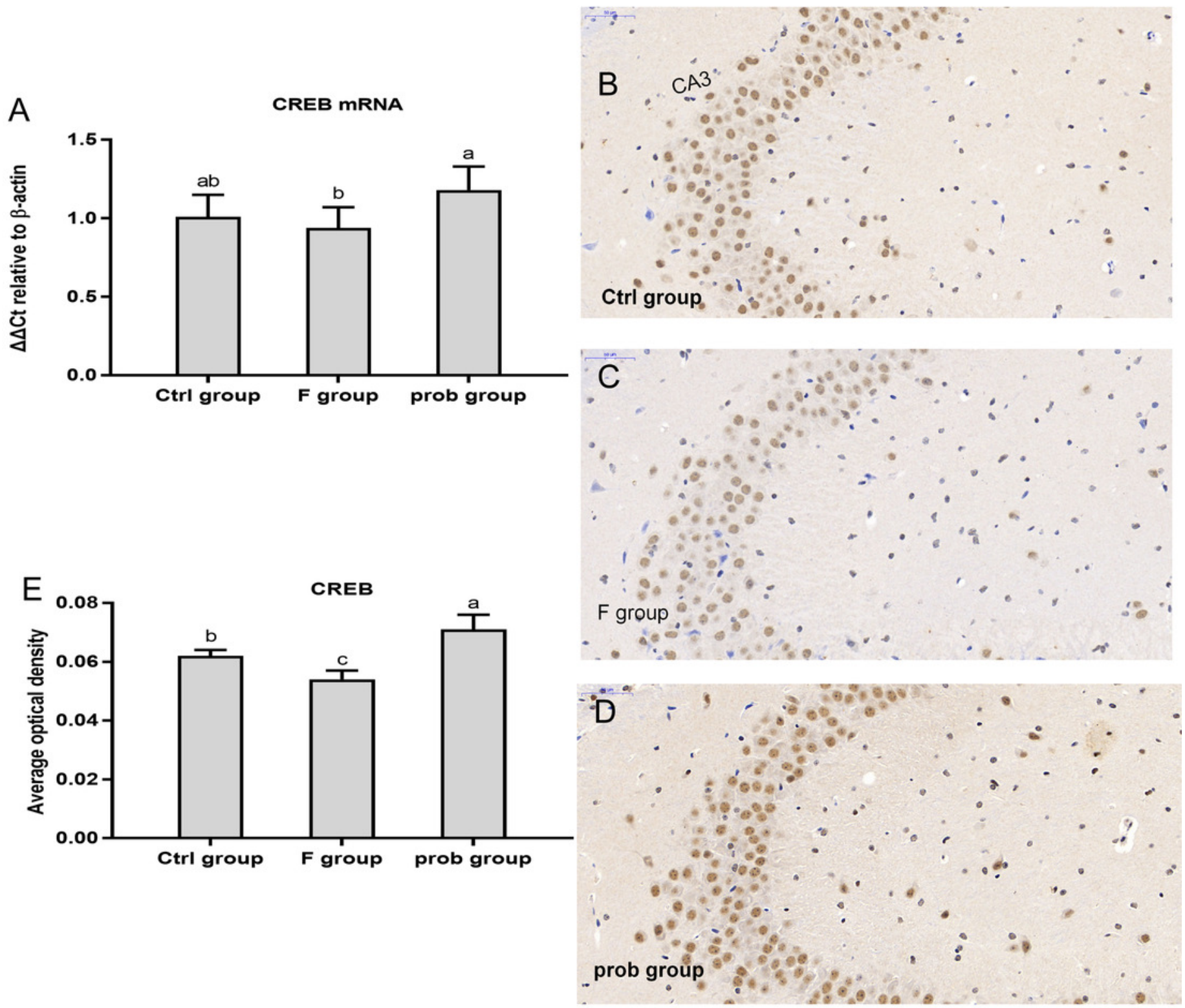
Figure 4

mRNA expressions of NCAM, SCF, and $c$-fos in the hippocampus.

Relative expression levels of (A) NCAM, (B) SCF, and (C) $c$-fos. Data are presented as mean \pm standard deviation $(n=4-5)$. Bars with different letters $(a, b$, and $c)$ indicate significant difference on the basis of Duncan's multiple range test $(P<0.05)$.
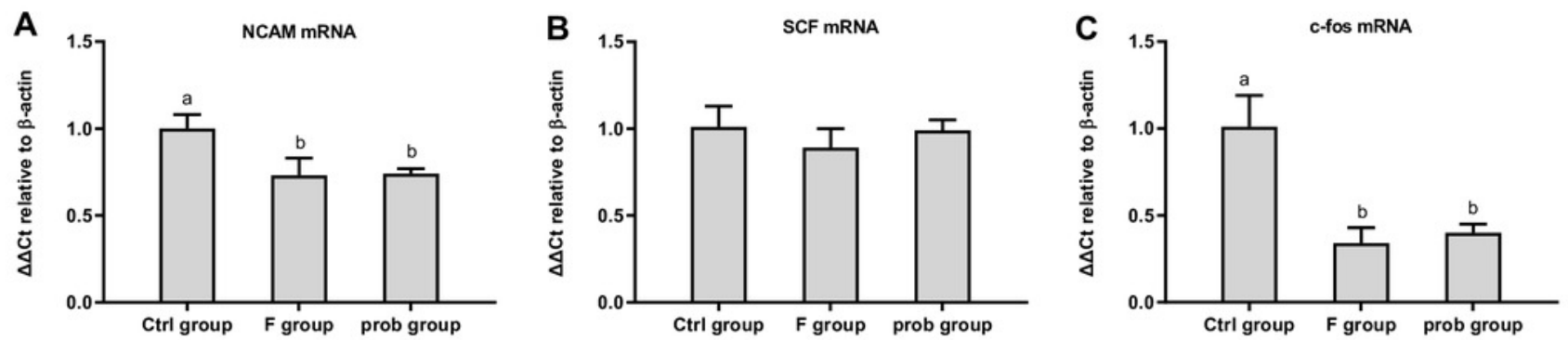
Figure 5

mRNA and protein expression levels of inflammatory cytokines in the hippocampus.

Relative expression levels of (A) TNF- $\alpha$, (B) IL- $\beta$, (C) IL- 6 , and (D) IFN- $\gamma$. Data are presented as mean \pm standard deviation $(n=4-6)$. Bars with different letters $(a, b$, and $c)$ indicate significant difference on the basis of Duncan's multiple range test $(P<0.05)$.
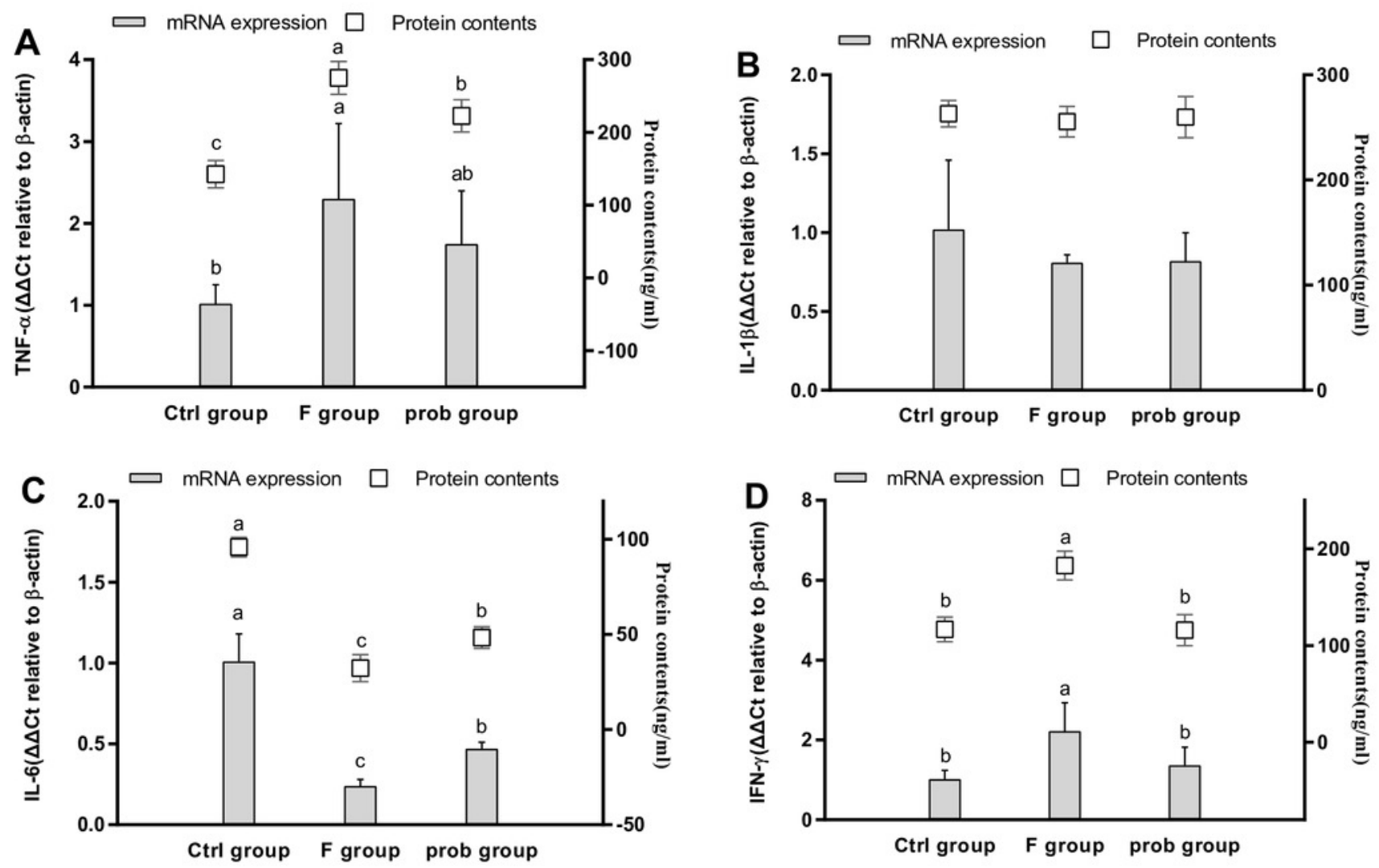
Figure 6

mRNA expression levels of myelin-associated proteins in the hippocampus.

Relative expression levels of (A) PLP, (B) MOG, (C) MBP, and (D) MAG. Data are presented as mean \pm standard deviation $(n=3-5)$. Bars with different letters $(a, b$, and $c)$ indicate significant difference on the basis of Duncan's multiple range test $(P<0.05)$.
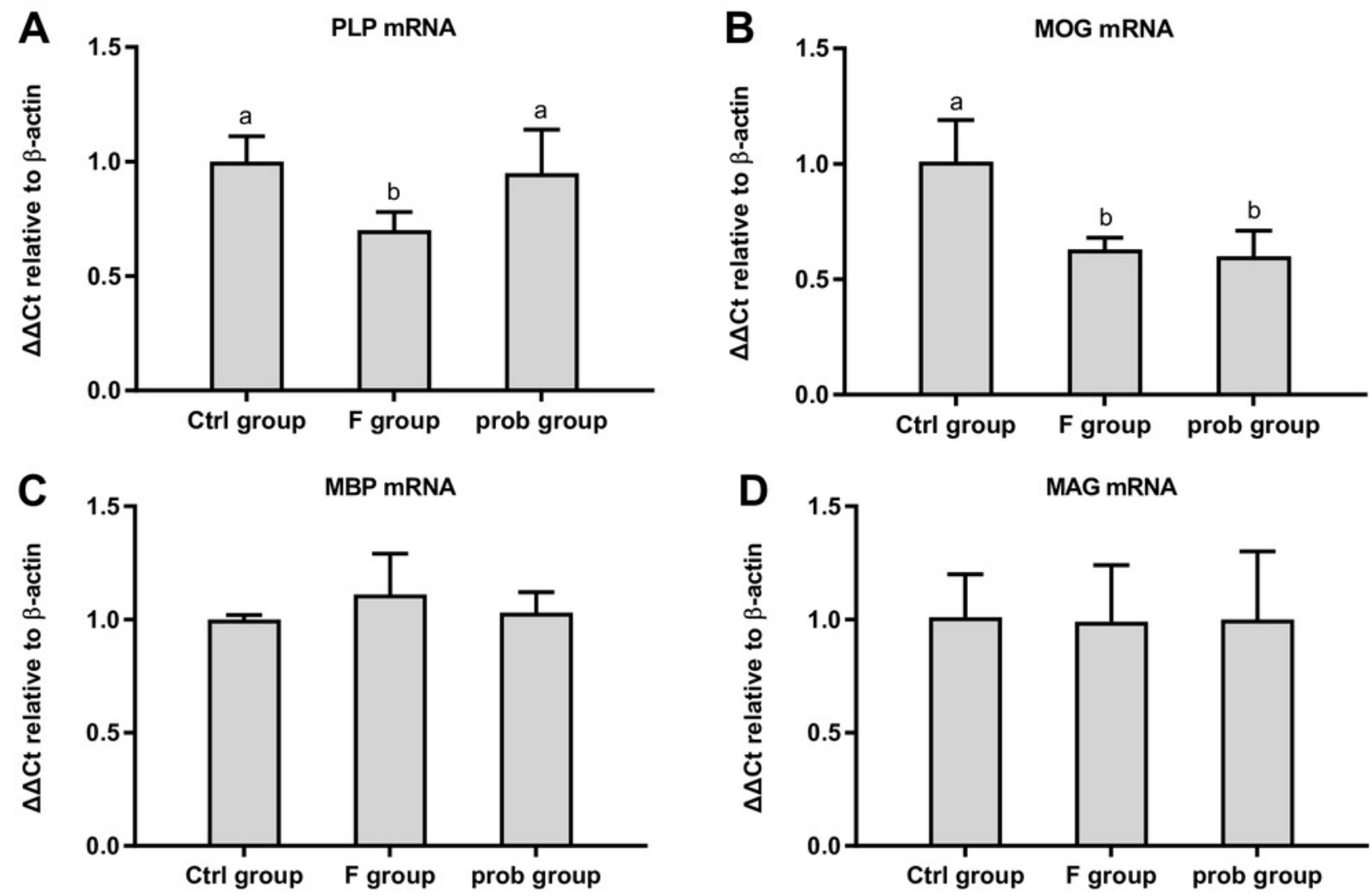


\section{Figure 7}

mRNA expressions levels of apoptosis-associated proteins in the hippocampus of mice.

Relative expression levels of (A) BCl-2, (B) BCl-xl, (C) Bax, (D) Bad, (E) caspase-3, and (F) caspase-9. Bars with different letters $(a, b$, and $c)$ are significantly different $(P<0.05)$ on the basis of one-way ANOVA. Each bar represents mean \pm standard deviation $(n=4-6)$. 

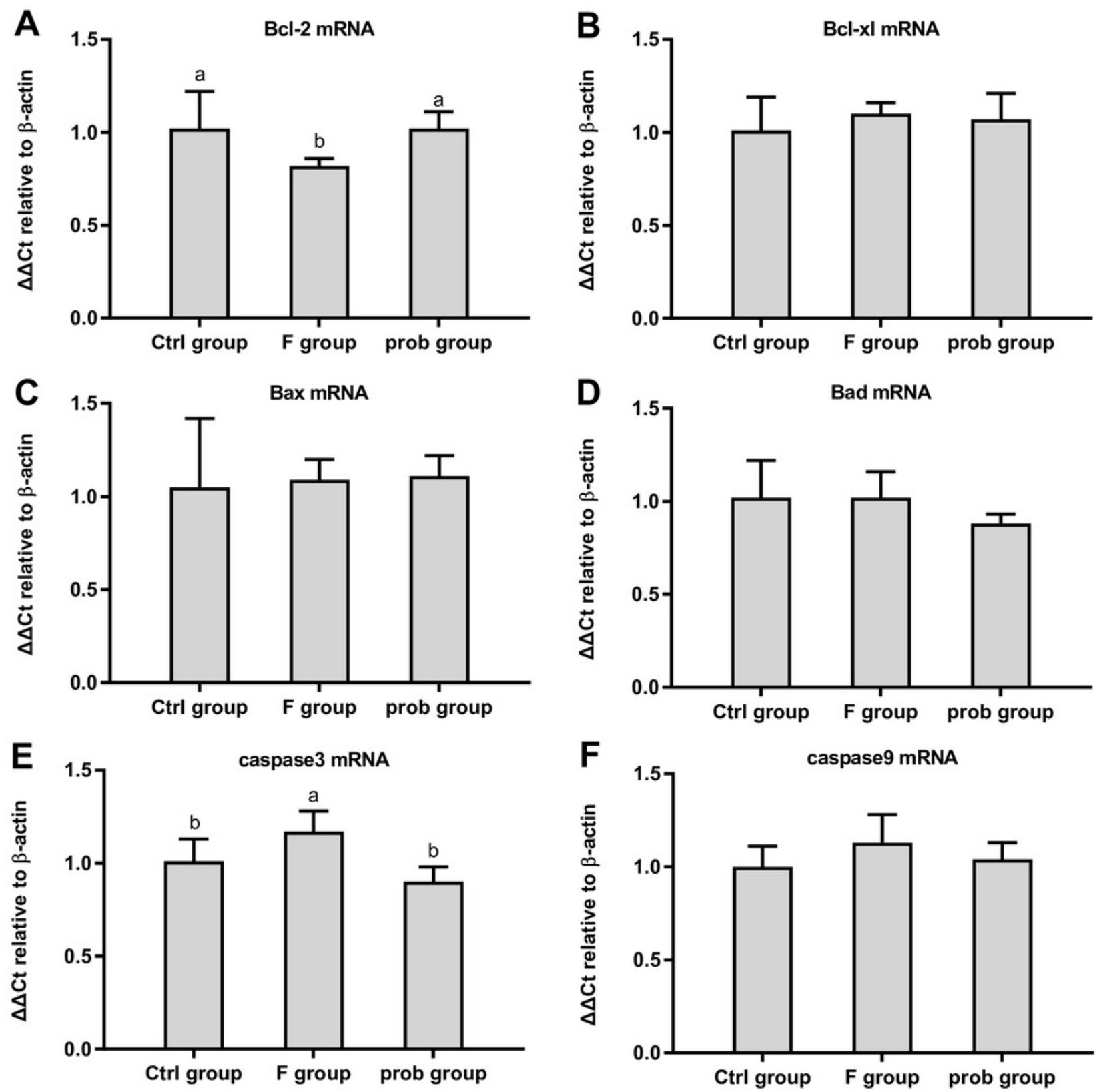
Figure 8

mRNA and protein expression levels of inflammatory cytokines in the ileum.

Relative expression levels of (A) TNF- $\alpha$, (B) IL- $\beta$, (C) IL-6, (D) IFN- $\gamma$, and (E) IL-10. Data are presented as mean \pm standard deviation $(n=4-6)$. Bars with different letters $(a, b$, and $c)$ are significantly different on the basis of Duncan's multiple range test $(P<0.05)$.
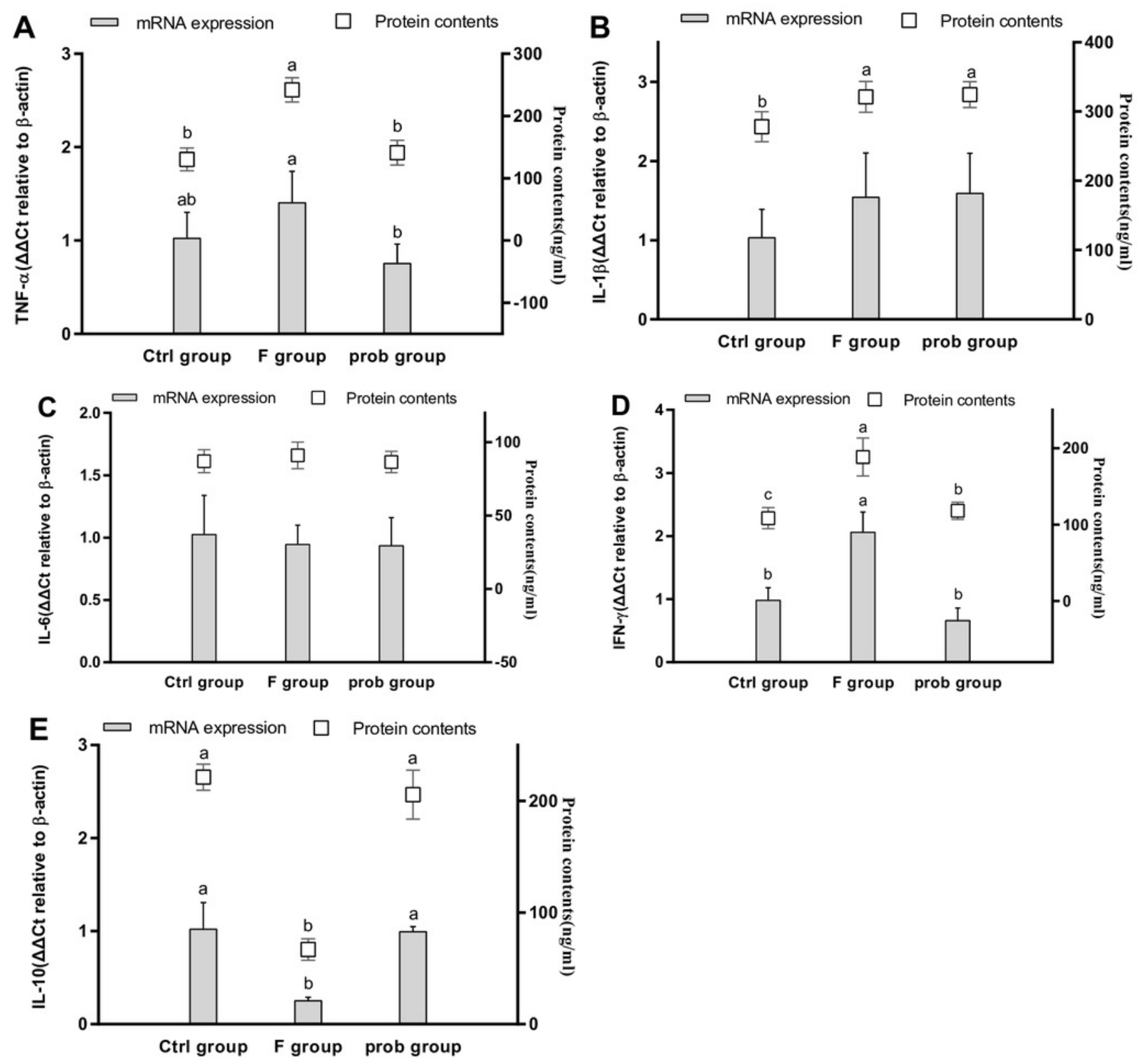
Figure 9

Results of intestinal permeability.

(A) mRNA expression levels of ZO-1, claudin-1, and occludin in the ileum, (B) Serum DAO activity, and (C) Serum D-lactate concentration. Data are presented as mean \pm standard deviation $(n=4-6)$. Bars with different letters $(a, b$, and $c)$ indicate significant difference on the basis of Duncan's multiple range test $(P<0.05)$.
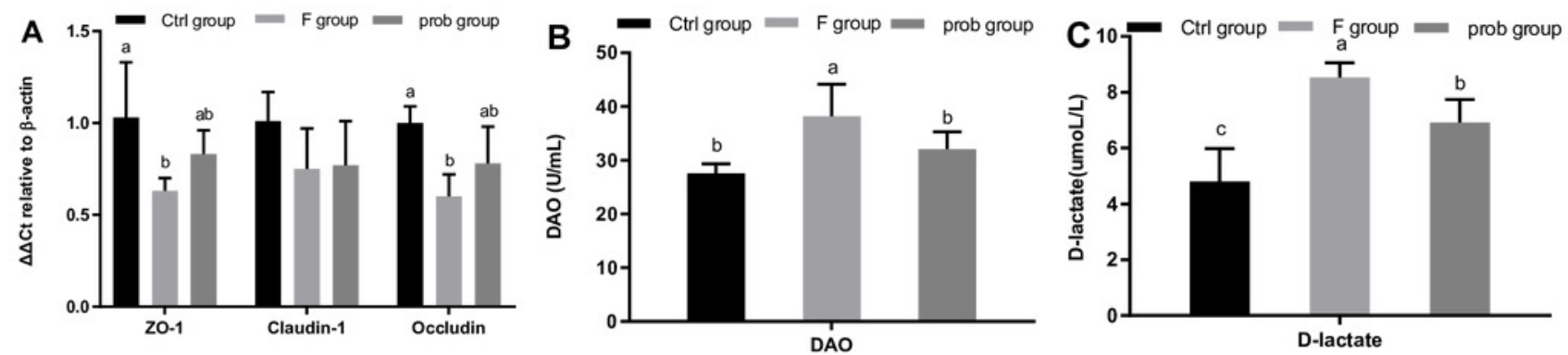